\title{
Seasonal evolution of soil and plant parameters on the agricultural Gebesee test site: a database for the set-up and validation of EO-LDAS and satellite-aided retrieval models
}

\author{
Sina C. Truckenbrodt and Christiane C. Schmullius \\ Fernerkundung, Institut für Geographie, Friedrich-Schiller-Universität Jena, Löbdergraben 32, \\ 07743 Jena, Germany \\ Correspondence: Sina Truckenbrodt (sina.truckenbrodt@uni-jena.de)
}

Received: 12 June 2017 - Discussion started: 12 July 2017

Revised: 15 January 2018 - Accepted: 18 January 2018 - Published: 13 March 2018

\begin{abstract}
Ground reference data are a prerequisite for the calibration, update, and validation of retrieval models facilitating the monitoring of land parameters based on Earth Observation data. Here, we describe the acquisition of a comprehensive ground reference database which was created to test and validate the recently developed Earth Observation Land Data Assimilation System (EO-LDAS) and products derived from remote sensing observations in the visible and infrared range. In situ data were collected for seven crop types (winter barley, winter wheat, spring wheat, durum, winter rape, potato, and sugar beet) cultivated on the agricultural Gebesee test site, central Germany, in 2013 and 2014. The database contains information on hyperspectral surface reflectance factors, the evolution of biophysical and biochemical plant parameters, phenology, surface conditions, atmospheric states, and a set of ground control points. Ground reference data were gathered at an approximately weekly resolution and on different spatial scales to investigate variations within and between acreages. In situ data collected less than 1 day apart from satellite acquisitions (RapidEye, SPOT 5, Landsat-7 and -8) with a cloud coverage $\leq 25 \%$ are available for 10 and 15 days in 2013 and 2014, respectively. The measurements show that the investigated growing seasons were characterized by distinct meteorological conditions causing interannual variations in the parameter evolution. Here, the experimental design of the field campaigns, and methods employed in the determination of all parameters, are described in detail. Insights into the database are provided and potential fields of application are discussed. The data will contribute to a further development of crop monitoring methods based on remote sensing techniques. The database is freely available at PANGAEA (https://doi.org/10.1594/PANGAEA.874251).
\end{abstract}

\section{Introduction}

Ground reference data are required for the set-up and validation of land data assimilation systems that enable large-scale monitoring of crop properties with Earth Observation data (Lillesand et al., 2008). The recently developed Earth Observation Land Data Assimilation System (EO-LDAS; Lewis et al., 2012) represents a weak-constraint variational land data assimilation system that relies on radiative transfer models describing the interaction of photons with canopy, leaves, and soil. EO-LDAS can be used in two different modes. In the forward mode, the surface reflectance of vegetated areas can be simulated in the visible and infrared domain for a given set of soil and vegetation parameters. In the inverse mode, Earth Observation data are interpreted in terms of soil and vegetation parameters, while prior information is introduced to diminish the uncertainty of retrieved parameters (cf. Chernetskiy et al., 2017).

Ground reference data for retrieval models that make use of satellite observations in the visual and infrared do- 

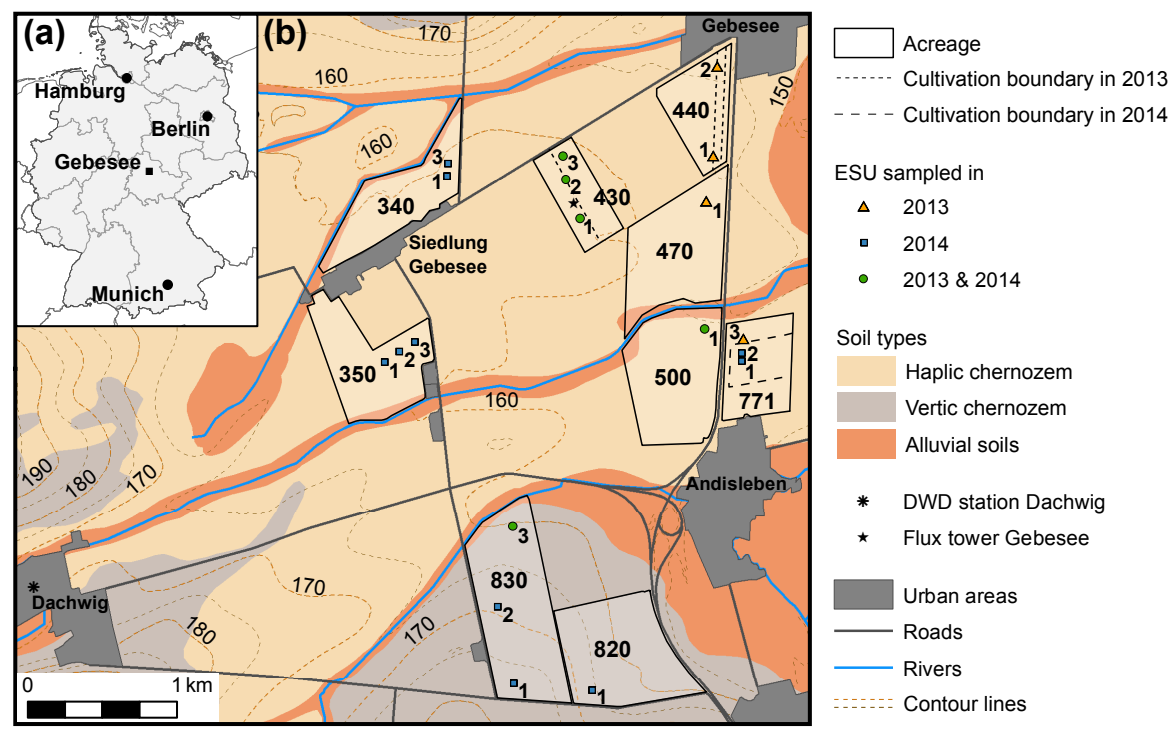

Figure 1. Location of (a) the Gebesee test site within Germany and (b) elementary sampling units (ESUs) on the acreages of the Geratal Agrar GmbH \& Co. KG Andisleben. Relief and predominant soil types are shown according to TLVermGeo (2008) and TLUG (2000, 2002), respectively. Urban areas, roads, and rivers were digitalized from TLVA (2003) and TLVermGeo (2006, 2010, 2012). The location and numbering of fields were taken from Döring (1988). Note the eddy covariance flux tower (MPI BGC, 2015) in the center of acreage 430 and the meteorological station of the DWD (Deutscher Wetterdienst; DWD, 2016) in Dachwig in the southwest.

main have been collected on NASA Earth Observing System (EOS) Land Validation Core (NASA, 2016) and JECAM (JECAM, 2015) sites (see Table A1 in the Appendix for acronyms used in this study). Further datasets were acquired during projects and campaigns such as BigFoot (ORNL DAAC, 2008), EnMAP (Hank et al., 2016), SPARC, SEN2FLEX, AquiferEx, AgriSAR 2006, CEFLES2, SEN3EXP, AgriSAR 2009, and HYFLEX (ESA, 2015).

Some of these ground reference datasets (e.g., SPARC, SEN2FLEX) provide information on a comprehensive set of vegetation parameters $(\geq 6)$, but the temporal resolution is rather low ( $<5$ measurement days per growing season). Other datasets (e.g., BigFoot, AgriSAR 2009) were elaborated with an enhanced temporal (up to weekly) resolution, but include only a few $(<6)$ vegetation parameters. While the acquisition of all these datasets is well aligned with specific project aims, none of the aforementioned datasets meets the requirements for comprehensive testing and validation of EO-LDAS. For the validation of the inverse mode, ground reference data must be available for various soil and vegetation parameters represented in EO-LDAS, while the set-up of detailed prior information on seasonal parameter variations necessitates a high temporal resolution. In addition, hyperspectral measurements are required for an in-depth validation of the forward mode.

Here, we present a comprehensive ground reference database for the set-up, test, and validation of EO-LDAS that may also be used in combination with satellite-aided retrieval models. The database contains information about the phenological evolution for seven crop types cultivated on the agricultural Gebesee test site in 2013 and 2014. Data on plant physiology, soil, and atmospheric conditions were collected with an approximately weekly resolution. Data acquisition was accompanied by hyperspectral measurements of surface reflectance factors. The measurement design, equipment, and methods are described in detail. Free access to the database is provided on PANGAEA (https://doi.org/10.1594/PANGAEA.874251, Truckenbrodt and Baade, 2017).

\section{Study area and site description}

The agricultural Gebesee test site $\left(51^{\circ} 05^{\prime} \mathrm{N}, 10^{\circ} 55^{\prime} \mathrm{E}\right.$; $150-180 \mathrm{~m}$ a.s.l.) is situated in the Thuringian Basin in central Germany (Fig. 1). Low relief energy and the predominance of fertile loess soils promote widespread agricultural land use in the region (Hiekel et al., 2004). Mean annual precipitation is rather low $(530 \mathrm{~mm}$; 1991-2014; DWD, 2015) because of rain shadow effects generated by the Thuringian Forest to the south and the Harz Mountains to the north (Bauer, 1959). Mean monthly rainfall varies from about $30 \mathrm{~mm}$ in February to about $80 \mathrm{~mm}$ in July. Average annual air temperature is about $9.5^{\circ} \mathrm{C}$, while mean monthly temperatures range from $0.8^{\circ} \mathrm{C}$ in January to $18.9^{\circ} \mathrm{C}$ in July (1991-2014; DWD, 2015). The growing season prevails from March to November, but the duration may vary depending on temperature (TLL, 2009). 
Table 1. Cultivation plan for the investigated acreages (see also Fig. 1).

\begin{tabular}{|c|c|c|c|c|c|c|}
\hline \multirow[t]{2}{*}{ Acreage no. } & \multicolumn{3}{|c|}{2013} & \multicolumn{3}{|c|}{2014} \\
\hline & $\begin{array}{l}\text { Species } \\
\text { cultivar }\end{array}$ & $\begin{array}{r}\text { Acreage size } \\
\text { (ha) }\end{array}$ & ESU & $\begin{array}{l}\text { Species } \\
\text { cultivar }\end{array}$ & $\begin{array}{r}\text { Acreage size } \\
\text { (ha) }\end{array}$ & ESU \\
\hline 340 & - & - & - & $\begin{array}{l}\text { winter rape } \\
\text { Brassica napus } \mathrm{L} . \\
\text { Exstorm }\end{array}$ & 37.02 & $\begin{array}{l}340-1 \\
340-3\end{array}$ \\
\hline 350 & - & - & - & $\begin{array}{l}\text { spring wheat } \\
\text { Triticum aestivum } \mathrm{L} \text {. } \\
\text { Taifun }\end{array}$ & 41.28 & $\begin{array}{l}350-1 \\
350-2 \\
350-3\end{array}$ \\
\hline \multirow[t]{2}{*}{$430^{\mathrm{a}}$} & $\begin{array}{l}\text { spring wheat } \\
\text { Triticum aestivum } \mathrm{L} \text {. } \\
\text { Taifun }\end{array}$ & 10.33 & $\begin{array}{l}430-1 \\
430-2\end{array}$ & \multirow[t]{2}{*}{$\begin{array}{l}\text { winter wheat } \\
\text { Triticum aestivum } \mathrm{L} \text {. } \\
\text { Mulan }\end{array}$} & \multirow[t]{2}{*}{21.24} & $\begin{array}{l}430-1 \\
430-2 \\
430-3\end{array}$ \\
\hline & $\begin{array}{l}\text { durum } \\
\text { Triticum durum Desf. } \\
\text { Floradur }\end{array}$ & 9.73 & $\begin{array}{l}430-2 \\
430-3\end{array}$ & & & \\
\hline \multirow[t]{2}{*}{$440^{\mathrm{b}}$} & $\begin{array}{l}\text { potato } \\
\text { Solanum tuberosum L. } \\
\text { Birgit }\end{array}$ & 4.04 & $\begin{array}{l}440-1 \\
440-2\end{array}$ & \multirow[t]{2}{*}{-} & \multirow[t]{2}{*}{-} & \multirow[t]{2}{*}{-} \\
\hline & $\begin{array}{l}\text { potato } \\
\text { Solanum tuberosum L. } \\
\text { Concordia }\end{array}$ & 11.55 & $\begin{array}{l}440-1 \\
440-2\end{array}$ & & & \\
\hline 470 & $\begin{array}{l}\text { winter barley } \\
\text { Hordeum vulgare } \mathrm{L} . \\
\text { Souleyka }\end{array}$ & 48.12 & $470-1$ & - & - & - \\
\hline 500 & $\begin{array}{l}\text { winter wheat } \\
\text { Triticum aestivum } \mathrm{L} \text {. } \\
\text { Genius }\end{array}$ & 49.26 & $500-1$ & $\begin{array}{l}\text { sugar beet } \\
\text { Beta vulgaris L. }\end{array}$ & 50.73 & $500-1$ \\
\hline 771 & $\begin{array}{l}\text { durum } \\
\text { Triticum durum Desf. } \\
\text { Floradur }\end{array}$ & 29.23 & $771-3$ & $\begin{array}{l}\text { potato } \\
\text { Solanum tuberosum } \mathrm{L} \text {. } \\
\text { Concordia }\end{array}$ & 8.57 & $\begin{array}{l}771-1 \\
771-2\end{array}$ \\
\hline 820 & - & - & - & $\begin{array}{l}\text { durum } \\
\text { Triticum durum Desf. } \\
\text { Floradur }\end{array}$ & 51.68 & $820-1$ \\
\hline 830 & $\begin{array}{l}\text { spring wheat } \\
\text { Triticum aestivum } \mathrm{L} \text {. } \\
\text { Taifun }\end{array}$ & 60.49 & $830-3$ & $\begin{array}{l}\text { winter barley } \\
\text { Hordeum vulgare L. } \\
\text { Laverda }\end{array}$ & 60.49 & $\begin{array}{l}830-1 \\
830-2 \\
830-3\end{array}$ \\
\hline
\end{tabular}

The Gebesee test site consists of nine acreages ranging in size from 8.57 to 60.49 ha (Table 1 ). The acreages are situated on fields 340, 350, 430, 440, 470, 500, and 771 in the northern and central parts of the test site and fields 820 and 830 in the south (Fig. 1b; https://doi.org/10.1594/PANGAEA.874249). The northern and central parts are characterized by fertile Haplic Chernozems (according to IUSS Working Group WRB, 2015) that developed on Quaternary loess deposits (Rau et al.,
2000; Anthoni et al., 2004). Relief energy is generally low in these areas, with slopes $<2.5^{\circ}$ (TLVermGeo, 2008). In the southern part, clayey sedimentary rocks of the Triassic Keuper formation (Rau et al., 2000) are typically associated with Vertic Chernozems (TLUG 2000; TLUG 2002). Here, slope inclination reaches up to $5^{\circ}$ (TLVermGeo, 2008). The fields are cultivated based on crop rotation by Geratal Agrar GmbH \& Co. KG Andisleben (Geratal Agrar). In 2013 and 2014, all investigated crops were entirely rain-fed. An eddy covariance 

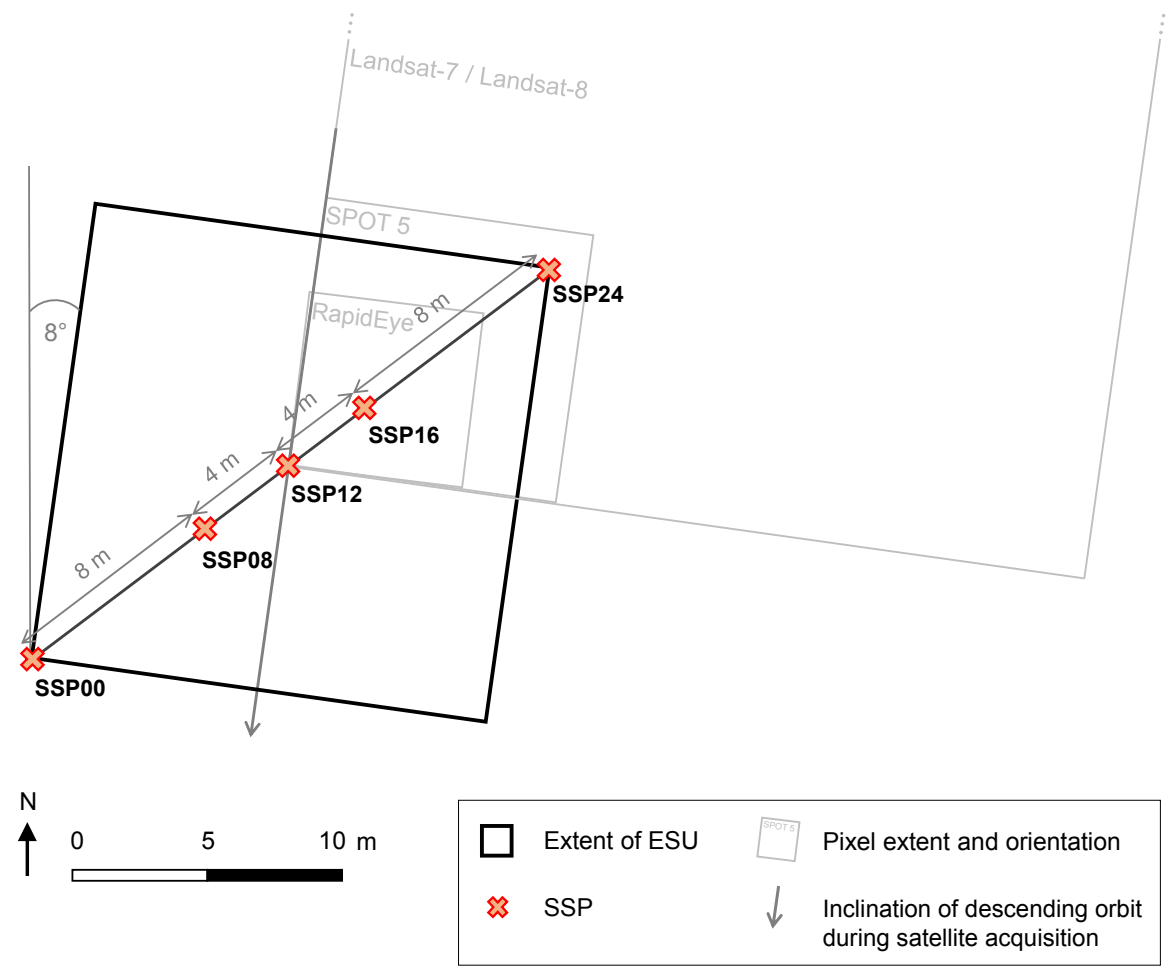

Figure 2. Design of elementary sampling units (ESUs). Each ESU contains five secondary sampling points (SSPs). The azimuthal orientation of the ESUs was chosen according to the inclination of the SPOT 5 and Landsat- 7 and -8 descending orbits. The figure illustrates the pixel size of images from various satellite sensors in comparison to the size of ESUs. The case with the smallest spatial coincidence between pixels and the ESU is depicted.

flux tower has been operated in the center of field 430 since 2000 (MPI BGC, 2015).

\section{Measurement design of the field campaigns}

Ground reference data were collected for several crop types, i.e., winter barley, winter wheat, spring wheat, durum, and potato throughout the cultivation periods of 2013 and 2014. In addition, data for winter rape and sugar beet were gathered in 2014 (Table 1). The selected crop types cover a wide range of canopy architectures and represent frequently cultivated crops at the mid-latitudes (USDA, 2015). Moreover, these crops are regularly grown on field 430, which occupies the major part of the flux tower footprint (Anthoni et al., 2004). This allows for the combination of current data with flux tower measurements.

Field measurements were carried out on various spatial scales by applying the concept of elementary sampling units (ESUs; Morisette et al., 2006). Up to three ESUs were established for each crop type to investigate spatial heterogeneity on the scale of acreages. ESUs were designed as squares with a diagonal length of $24 \mathrm{~m}$. Edges of the ESUs were oriented with an azimuth angle of approximately $8^{\circ}$, which is in accordance with the orbit inclination of SPOT 5 and Landsat-7 and -8 (Fig. 2). ESUs were installed at least $90 \mathrm{~m}$ (i.e., 3 times the Landsat-8 OLI pixel length) from neighboring acreages and areas with differing land cover (e.g., flower strips). This facilitates comparison between satellite imagery and ground reference data as it avoids issues arising from mixed pixels and adjacency effects.

Each ESU consists of five secondary sampling points (SSPs) that permit an assessment of spatial heterogeneity on the scale of ESUs. On each ESU, SSPs were established along the $24 \mathrm{~m}$ long diagonal running from the southwestern to northeastern corners (Fig. 2). SSPs were located 0 , $8,12,16$, and $24 \mathrm{~m}$ from the southwestern corner and are labeled SSP00, SSP08, SSP12, SSP16, and SSP24, respectively. Spacing between SSPs permits the simulation of subpixel variability in satellite data acquired with medium resolution sensors carried by RapidEye, SPOT 5, and Landsat-7 and -8 . In order to minimize disturbance on acreages and ESUs, measurement points were accessed via tractor lanes and $<0.5 \mathrm{~m}$ wide paths leading along the SSPs.

In 2013, acreage 430 was split with spring wheat and durum being cultivated in the western and eastern parts, respectively (Table 1). The split became apparent only after the start of the measurements. ESU 430-1 and SSP00 to SSP16 of ESU 430-2 represent spring wheat, while durum grew 


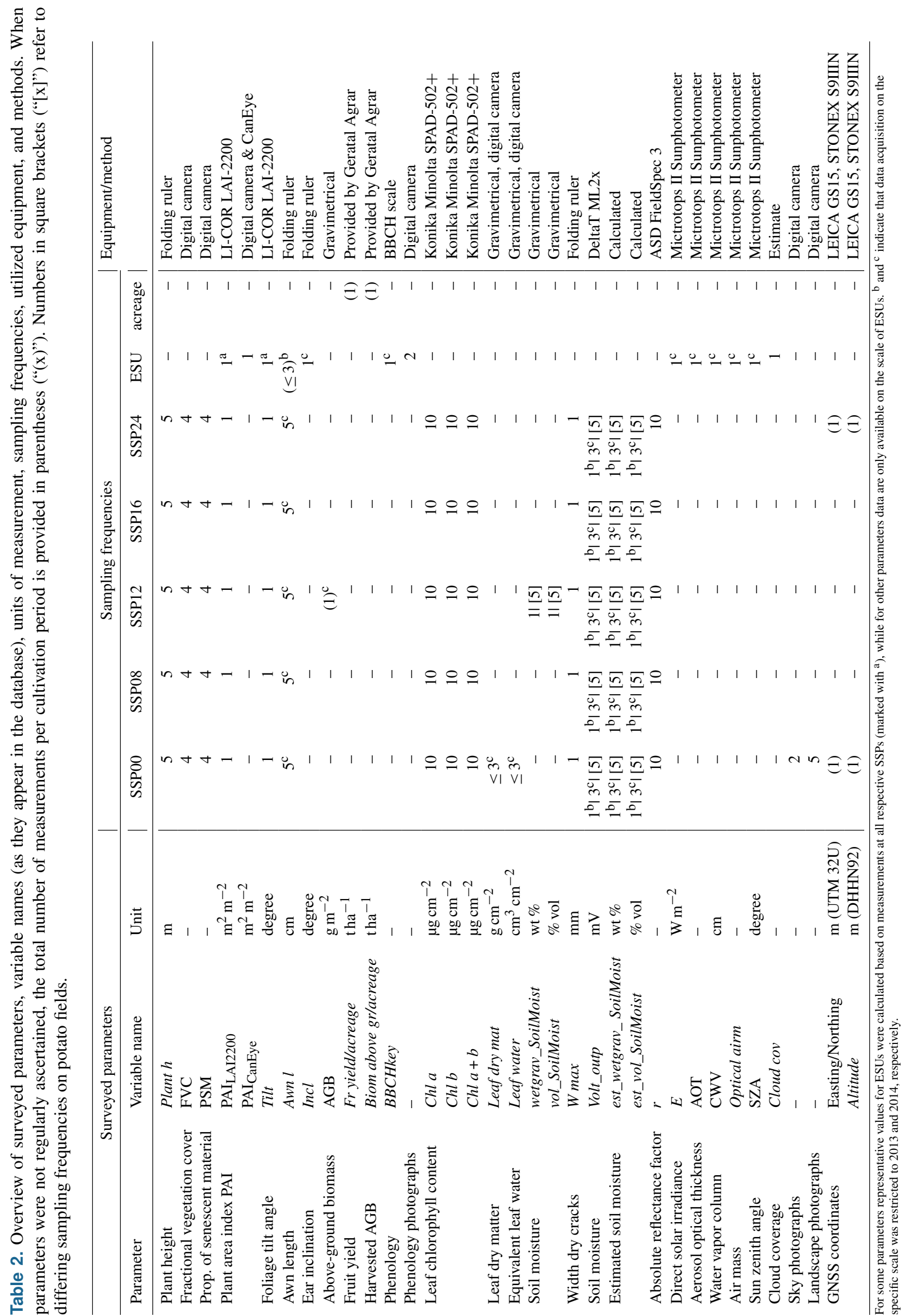




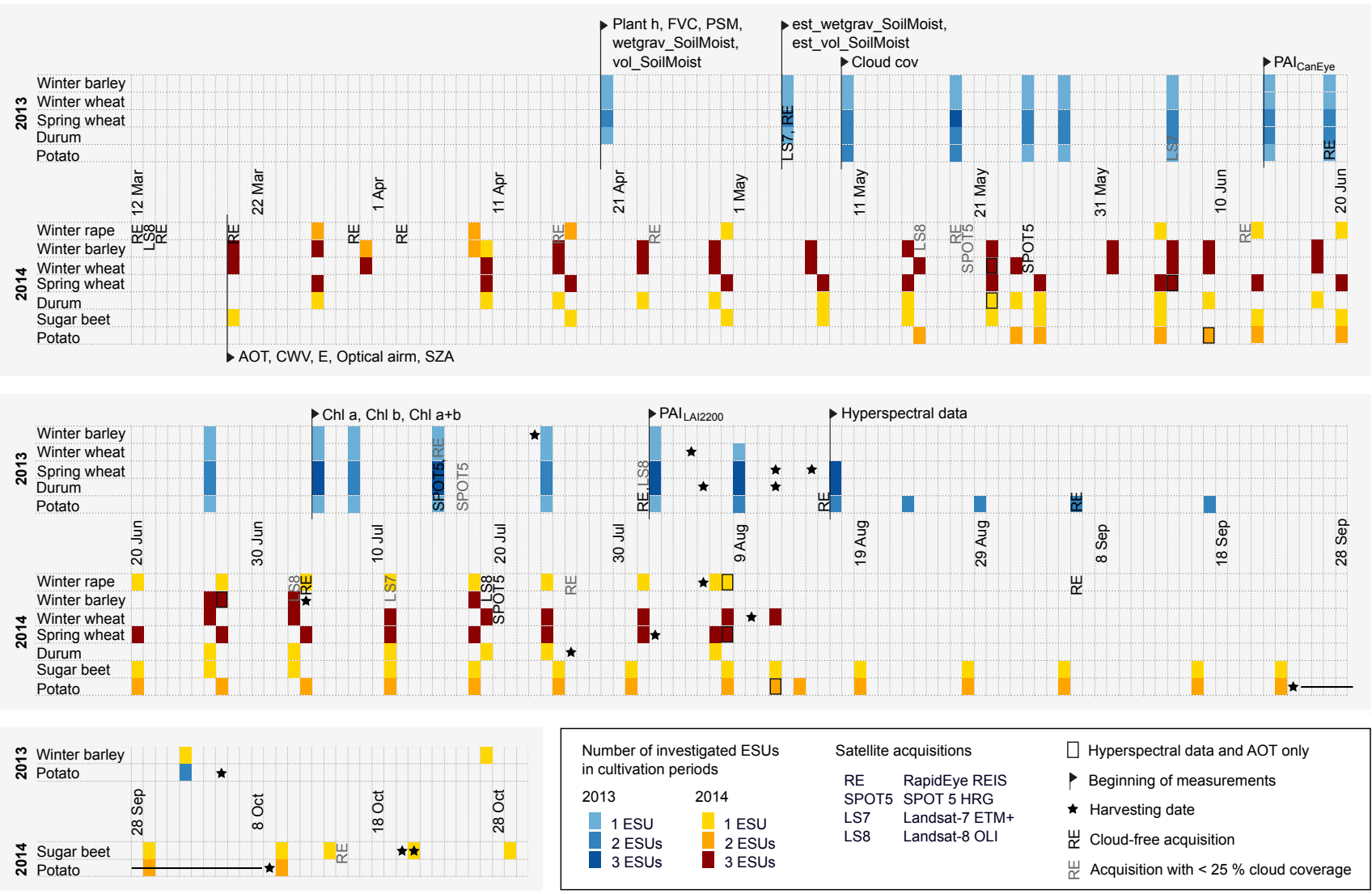

Figure 3. Overview of days of field work carried out on the Gebesee test site to ascertain the phenological evolution of various crop types on elementary sampling units (ESUs) throughout the cultivation periods 2013 (yellow to red) and 2014 (light to dark blue), and availability of space-borne images with $<25 \%$ of the test site covered with clouds. The measurement start varied between the parameters investigated in 2013, while complete datasets are available for the entire cultivation period in 2014.

on SSP24 of ESU 430-2 and the entire ESU 430-3. This notwithstanding, the measurements provide valuable information, in particular, as both crop types were situated within the footprint of the eddy covariance flux tower that was located $30 \mathrm{~m}$ from the cultivation boundary. In 2014, this was not an issue since the entire acreage 430 was cultivated with winter wheat.

Field work was carried out with approximately weekly resolution taking into account the local weather forecast. Field measurements were preferentially scheduled for days with a high probability of low cloud coverage, since the occurrence of haze and clouds interferes with hyperspectral measurements (Gilabert and Meliá, 1993). In addition, we attempted to synchronize days of field work with acquisition plans of RapidEye, SPOT 5, Landsat-7, and -8.

Measurement frequency differed between parameters and SSPs as shown in Table 2. In 2014, investigations were conducted consistently throughout the cultivation period, while the measurement start varied between different parameters in 2013. Most parameters were surveyed from the beginning of the cultivation period, but the measurement start for plant area index, leaf chlorophyll content, and hyperspectral data was delayed (Fig. 3). Monitoring of equivalent leaf water, leaf dry matter, aerosol optical thickness, and column water vapor was entirely restricted to 2014 .

\section{Ground measurements}

Unless stated otherwise, data for parameters introduced in this chapter are available via the PANGAEA datasets for 2013 (https://doi.org/10.1594/PANGAEA.874158) and 2014 (https://doi.org/10.1594/PANGAEA.874235).

\subsection{Biophysical plant parameters}

\subsubsection{Plant height}

Plant height (Plant $h$ ) is a key parameter for the description of the canopy architecture in radiative transfer models as it determines the thickness of the layer in which photons interact with plant compartments (Gobron et al., 1997). Plant height was determined with a folding ruler as the distance 
from the soil surface to the top of canopy. At each SSP, five measurements were carried out in a $1 \mathrm{~m}$ circuit. A reduction in plant height is determined when ears of cereals are drooping or when cornstalks are flattened before harvesting.

\subsubsection{Fractional vegetation cover and proportion of senescent material}

Fractional vegetation cover (FVC; Purevdorj et al., 1998) depicts the relative proportion of vegetated areas and is, thus, an indicator of the relative contribution of the soil and vegetation signals to the top of canopy reflectance. The vegetation signal itself varies strongly between green and senescent plant compartments. To account for this, the proportion of senescent material (PSM) was ascertained with respect to the overall vegetated area. FVC and PSM were determined from nadir photos. At each SSP, two nadir photos were taken $1.2 \mathrm{~m}$ above the ground and $1 \mathrm{~m}$ above the top of canopy, respectively. Photos were alternatively captured with a Nikon D300s (equipped with a AF-S DX NIKKOR $16-85 \mathrm{~mm}$ 1:3.5-5.6G ED VR) and a Nikon D5000 (equipped with a TAMRON AF 18-200 mm F/3.5-6.3 [IF] MACRO Ø62 A14) with focal length set to $18 \mathrm{~mm}$. From these photos, FVC and PSM were determined by applying an automatic twostep pixel-based hierarchical classification procedure that was implemented in the $\mathrm{R}$ software environment (version 3.2.3; R Core Team, 2015). The following classes of pixels were distinguished: "soil", "green vegetation", and "senescent vegetation".

Nadir photos were acquired under varying illumination conditions. Previous work indicates that hue values are far less affected by illumination conditions than RGB (red, green, blue) values (Liu and Moore, 1990). Thus, all nadir photos were transformed to the HSL (hue, saturation, lightness) color space (Motonaga et al., 2004).

In the first classification step, soil pixels were distinguished from non-soil pixels with the help of a look-up table. A pixel was ascribed to the class "soil" when the saturation fell below a threshold that depends on hue $(\mathrm{H})$ and lightness (L). In the second step, a non-soil pixel was classified as "green vegetation" if the $\mathrm{H}$ values fell in between 42 and 135 (i.e., a greenish shade) and $\mathrm{L}$ exceeded a threshold that depends on $\mathrm{H}$. Remaining non-soil pixels were categorized as "senescent material". Since small bright soil particles were frequently misclassified as "green vegetation" or "senescent vegetation", pixels initially ascribed to these classes were clumped together with horizontally and vertically adjacent vegetation pixels and reclassified as "soil" if the related object comprised less than 200 pixels. Afterwards, a circular area with a diameter of 2648 pixels around the principle point of the photo was extracted. This corresponds to circles with diameters of about 1 and $0.85 \mathrm{~m}$ on the ground and top of canopy, respectively. Within the masked area, the classification results were evaluated statistically to obtain FVC and PSM which may range between 0 and 1 .
Bias and precision of FVC and PSM were assessed separately for each species, based on one arbitrarily selected ESU from which $\geq 10$ images were analyzed. In order to take into account different phenological, soil, and illumination conditions, we ensured that the acquisition dates of the selected images were regularly distributed throughout the cultivation period. From each image, a validation set consisting of 300 pixels was created using a stratified random sampling procedure implemented in Geomatica 2013 (PCI Geomatics, 2013). The proportion of pixels from each class in the validation set corresponded to the class percentage in the image according to classification results. All pixels in the validation set were visually inspected and ascribed to the appropriate class to obtain reference values against which classification results were compared. For each image the bias $X_{\text {bias }}$ in the determined proportion of pixels representing vegetation $(X=\mathrm{FVC})$ and "senescent vegetation" $(X=\mathrm{PSM})$ was calculated with Eq. (1),

$X_{\text {bias }}=\frac{n \operatorname{Class}_{X}-n \operatorname{Ref}_{X}}{n \operatorname{Ref} f_{\text {all }}}$,

where $n \operatorname{Ref}_{X}$ and $n \operatorname{Class}_{X}$ represent the number of pixels which were ascribed to class $X$ by means of visual inspection and automatic classification, respectively; $n R e f_{\text {all }}$ specifies the number of all pixels that were involved in the validation. Mean and standard deviation of $X_{\text {bias }}$ were determined for each species from all considered images and are provided on PANGAEA (https://doi.org/10.1594/PANGAEA.874144).

\subsubsection{Plant area index}

The plant area index (PAI), i.e., the leaf area index (LAI) including ears and cornstalks (Neumann et al., 1989), is an important canopy structural parameter in radiative transfer models and retrieval models in general (Gobron, 2008). PAI was ascertained in two different ways: (1) with the LAI-2200 Plant Canopy Analyzer (LAI-2200; LI-COR Biosciences, Inc.) and (2) based on digital hemispherical photos (DHPs). Both methods rely on the determination of the gap fraction (Ross, 1981), permit repetitive non-destructive measurements (Morisette et al., 2006), and were deployed complementarily. While PAI values obtained from the LAI-2200 method are available on the scale of SSPs and ESUs, PAI values derived from DHPs are only provided for entire ESUs.

LAI-2200 measurements were carried out following the recommendations of LI-COR (2012) for "row crops". The gap fraction was determined based on $2 \times 4$ measurements along $0.5 \mathrm{~m}$ long transects running diagonally between neighboring planting rows. The sensor lens was covered with a $45^{\circ}$ view cap with the field of view (FOV) oriented parallel and orthogonal to the planting rows, respectively. Direct solar irradiance should be avoided in LAI-2200 measurements (LI-COR, 2012). Thus, the sensor and part of its FOV were shaded with an umbrella. Processing of raw data was conducted with the FV2200 software (version 1.2; LI-COR Bio- 


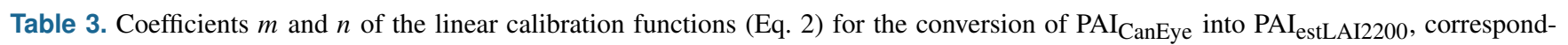

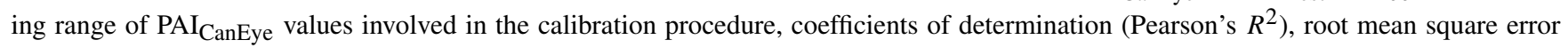
(RMSE), and sample number $(N)$.

\begin{tabular}{lrrrrrrr}
\hline Species & $m$ & $n$ & $\min$ & $\max$ & $R^{2}$ & RMSE & $N$ \\
\hline winter barley & 0.5380 & 0.2882 & 0.183 & 9.104 & 0.53 & 1.4 & 47 \\
winter wheat & 0.5740 & 0.1550 & 0.000 & 9.418 & 0.82 & 0.7 & 61 \\
spring wheat & 0.4987 & 0.2451 & 0.133 & 7.013 & 0.80 & 0.5 & 55 \\
durum & 0.5425 & 0.3352 & 0.109 & 7.105 & 0.88 & 0.5 & 20 \\
potato & 0.4771 & 0.3922 & 0.001 & 7.263 & 0.57 & 1.1 & 43 \\
sugar beet & 0.6305 & 0.5096 & 0.059 & 9.999 & 0.80 & 1.3 & 22 \\
winter rape & 0.5072 & 1.3676 & 0.186 & 8.305 & 0.70 & 1.2 & 16 \\
\hline
\end{tabular}

sciences, Inc., 2010). The gap fraction was determined in five concentric rings defined by central zenith angles of $7,23,38$, 53 , and $68^{\circ}$. In the course of the calculations uniform distribution of the canopy in the horizontal direction was assumed and the apparent clumping factor (ACF) following Ryu et al. (2010) was applied. The calculations reveal a parameter set including the PAI $\mathrm{LAI}_{2200}$ that is close to the "true" PAI (cf. Weiss et al., 2004), PAI standard error (SE PAI $\mathrm{L}_{\text {LAI2200), frac- }}$ tion of sky (FoS), mean foliage tilt angle (Tilt), and related standard error (SE Tilt; LI-COR, 2012). For the computation of ESU-wide parameter sets with the FV2200 software, raw data from all corresponding SSPs were combined.

In addition, ESU-wide PAI CanEye $_{\text {was }}$ determined from DHPs by applying the CAN-EYE V6.313 software (INRA EmmaH, 2014). DHPs were captured with a Nikon D300s (resolution: $4288 \times 2848$ pixels) and Nikon D5100 (resolution: $4928 \times 3264$ pixels) equipped with an AF DX FISHEYE-NIKKOR (10.5 mm $1: 2.8 \mathrm{G} \mathrm{ED})$. The height of the camera including the lens is about $12 \mathrm{~cm}$. Following Weiss et al. (2004), 10 DHPs per ESU (2 per SSP) were acquired in nadir and zenith view when plant heights were $\leq 25$ and $>25 \mathrm{~cm}$, respectively. DHPs were taken at a distance of approximately $1 \mathrm{~m}$ from the ESU diagonal to prevent an influence of the disturbed canopy architecture. For upward acquisitions, the camera was placed on the ground between neighboring planting rows to preserve the canopy structure. On potato fields, photos were taken in the middle of neighboring plants on top of the ridge and from the bottom of the furrow, respectively. Downward photos were generally acquired $0.3 \mathrm{~m}$ above the top of canopy.

DHPs were pre-processed using the "rtiff" $\mathrm{R}$ software package (Kort, 2014). For upward photos, the "intensitymean" (Xu et al., 2004) of each pixel was calculated. Pixels were assigned to the classes "vegetation" and "sky" by applying the Ridler clustering method (Ridler and Calvard, 1978) to the intensity-mean layer as recommended by Jonckheere et al. (2005). If significant misclassification occurred due to low brightness differences between sunlit vegetation and blue sky, the Ridler clustering was applied to the "excess blueness" layer (Xu et al., 2004). Downward photos were bina- rized according to the classes "vegetation" and "soil" by employing the classification algorithm described in Sect. 4.1.2 without distinguishing between green and senescent vegetation.

Classification artifacts resulting from perturbing objects (e.g., legs of the photographer) and overexposed parts in the DHPs were masked out manually with the KolourPaint software (version 4.14.1; KDE, 2013) that permits lossless storage of binary files in tagged image file (TIF) format. Afterwards, circular areas of interest were extracted with a radius equal to the minimal distance between the optical center (Baret, 2004) and the border of the image. The circular area of interest corresponds to a view angle of 42.5 and $37.5^{\circ}$ for the upward and downward photos, respectively. Files were imported into the CAN-EYE V6.313 software (INRA EmmaH, 2014) and the "true" PAI (PAI CanEye $)$ of each ESU was calculated with the CAN-EYE V5.1 formula (Weiss and Baret, 2014).

Starting in June 2013, at least one of the two methods was employed on each day of field work. The methods were employed alternatively, but depending on the crop type, between 16 and 61 pairs of values from simultaneous measurements are available (Table 3). PAI LAI2200 $_{2}$ and PAI CanEye values were found to differ by up to 5.97 with a median deviation of 2.17. Thus, species-specific linear calibration functions (Eq. 2) were set up to establish consistent and comparable time series of ESU-wide PAI (PAI $\mathrm{PstLAI2200}$ ) values:

$\mathrm{PAI}_{\mathrm{estLAI} 2200}=m \cdot \mathrm{PAI}_{\text {CanEye }}+n$.

Coefficients $m$ and $n$ were derived from pairs of values of

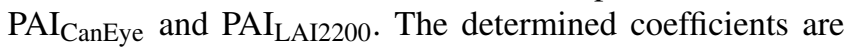
shown in Table 3 and are supplemented by the Pearson coefficient of determination $\left(R^{2}\right)$, the root mean square error

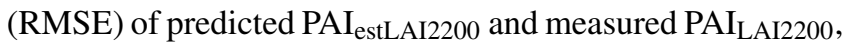
the calibration ranges, and the number of utilized pairs $N$.

\subsubsection{Awn length and ear inclination}

Besides leaves, ears influence the canopy reflectance of cereals. The contribution of ears varies with the awn length 
(Awn l) and the ear inclination (Incl; Zou and Mõttus, 2015). Awn length was determined with a folding ruler at awns springing on the top of the ear. In 2013, individual measurements were carried out on 0 to 3 field working days per ESU. In 2014, awn length was determined regularly for five ears located in a $1 \mathrm{~m}$ circuit of each SSP. Complementary mode, minimum, and maximum ear inclination was estimated once per ESU, in 2014. Angles of 0 and $180^{\circ}$ correspond to a vertical ear with the top up and down, respectively.

\subsubsection{Above-ground biomass and yield}

Above-ground biomass (AGB) has been used previously as an indicator of the density of plant compartments that can interact with radiation (e.g., Park and Deering, 1982). Moreover, AGB is an essential parameter for synthetic aperture radar (SAR) applications and is also useful for the prediction of crop yields (Mattia et al., 2003). In 2014, dry AGB was determined once per ESU, on average 10 days before harvesting. All above-ground plant compartments situated in a surface square area of $1 \times 1 \mathrm{~m}$ around SSP12 were removed, stored in a plastic bag for transport, and oven-dried at $52{ }^{\circ} \mathrm{C}$ until a constant weight was reached. Afterwards, the dry-weight biomass was determined. Moreover, data on fruit yields (Fr yield/acreage) in 2013 and 2014 were provided by Geratal Agrar for the acreages where ESUs were installed. In 2014, Geratal Agrar provided additional information on the harvested AGB ('Biom above gr/acreage) of winter wheat, i.e., fruit yield and straw, that was cultivated on acreage 430 .

\subsubsection{Phenology}

Phenological development stages create a basis for the comparison of biophysical and biochemical parameters of crops growing under different climatic, soil, illumination, and management conditions (Hank et al., 2015). Phenological development (BBCHkey) on each ESU was documented in 2014 by applying the growing stage keys of the extended $\mathrm{BBCH}$ scale (Meier, 2001). The BBCHkey can range between 0 (i.e., dry seed) and 99 (i.e., harvested product), while specific numbers correspond to defined stages of the phenological evolution. For example, values between 60 and 69 refer to the principal growth state of flowering. In addition, crops were photographed with a Nikon D5000 in vertical and oblique view to enhance the documentation of phenological states. Photos feature a folding ruler for scale. The phenology photos from 2013 (https://doi.org/10.1594/PANGAEA.874698) and 2014 (https://doi.org/10.1594/PANGAEA.874699) can be downloaded from PANGAEA.

\subsection{Leaf structural and biochemical parameters}

\subsubsection{Chlorophyll content}

Leaf chlorophyll pigments absorb radiation in the blue and red domain and play an important role in the assessment of the physiological status of the vegetation and the quantification of the photosynthetic activity (Blackburn, 1998). Content of leaf chlorophyll $a(C h l a)$ and $b(C h l b)$, and the sum of chlorophyll $a$ and $b(C h l a+b)$, were derived from nondestructive absorbance measurements (ChlSPAD) with the SPAD-502Plus chlorophyll meter (Konica Minolta, Inc.). Within a circuit of $1 \mathrm{~m}$ around each SSP, 10 readings were taken following the instructions of Konica Minolta (2012). Since major parts of the canopy reflectance in the visible range result from the uppermost leaves (Monteith, 1969), 7 of 10 ChlSPAD readings were taken in the upper two-thirds of the plants. The remaining three measurements were taken from leaves located rather close to the ground.

The dimensionless ChlSPAD values were converted into chlorophyll contents (in $\mu \mathrm{g} \mathrm{cm}^{-2}$ ) with crop type specific calibration functions (Table 4). For the set-up of these functions about 20 leaves were sampled for each investigated species in the field. Mean ChlSPAD values were determined from five ChlSPAD readings covering a circular area with a diameter of $7.3 \mathrm{~mm}$. Afterwards, these leaf disks were punched out and transferred into Eppendorf tubes that were subsequently transported in a Dewar flask filled with liquid nitrogen. Samples were stored at $-80^{\circ} \mathrm{C}$ in a freezer until lab analysis. Chlorophyll was extracted with a lab stirrer (RZR 2102 control, Heidolph Instruments $\mathrm{GmbH} \& \mathrm{Co}$. KG) while adding $80 \%$ buffered acetone (Porra and Grimme, 1974). After a minimum resting time of $15 \mathrm{~min}$, cooled samples were centrifuged $\left(10 \mathrm{~min}\right.$ at $\left.4{ }^{\circ} \mathrm{C} ; 16100 \mathrm{rcf}\right)$ and the extract decanted. The absorption of the extract was determined at 647, 664, and $750 \mathrm{~nm}$ with a UV-160A UV-Visible Recording Spectrophotometer (Shimadzu Corp.) and the chlorophyll content was calculated with the formula of Lichtenthaler and Buschmann (2001). Following Markwell et al. (1995), an exponential relationship (Eq. 3)

$C h l X=k \cdot e^{l \cdot C h l S P A D}$

was assumed between ChlSPAD readings and chlorophyll contents $C h l a, C h l b$, and $C h l a+b$ (in $\mu \mathrm{g} \mathrm{cm}^{-2}$; represented by $C h l X)$. Calibration coefficients $k$ and $l$ were determined separately for Chl $a, C h l b$, and Chl $a+b$ (Table 4). Pearson's coefficient of determination $\left(R^{2}\right)$ was used as a measure of goodness for the calibration equation.

Accuracy and precision of ChlSPAD readings were ensured by 30 measurements with a SPAD-502Plus reading checker (Konica Minolta, 2012) that were performed before and after the field working days. Biases range from -1.5 to 1.2 , with a median of -0.1 , which is below the tolerance of \pm 3.0 indicated by the manufacturer. The $1 \sigma$ errors vary between 0.1 and 0.7 , with a median of 0.1 . The measurement precision of the spectrophotometer was ascertained by 75 periodically collected triplicate determinations. The triplicate determinations reveal chlorophyll contents with a median $1 \sigma$ error on the order of $0.1 \mu \mathrm{g} \mathrm{cm}^{-2}$ and reach maximum $1 \sigma$ errors of $2.3,1.1$, and $3.4 \mu \mathrm{g} \mathrm{cm}^{-2}$ for Chl $a$, Chl b, and Chl $a+b$, respectively. 
Table 4. Coefficients $k$ and $l$ of the exponential calibration functions (Eq. 3) for the conversion of ChlSPAD values into Chl $a$, Chl $b$, and $C h l a+b$ content (in $\mu \mathrm{g} \mathrm{cm}^{-2}$ ), corresponding coefficients of determination (Pearson's $R^{2}$ ), and range of ChlSPAD values involved in the calibration procedure.

\begin{tabular}{|c|c|c|c|c|c|c|c|c|c|c|c|}
\hline \multirow[t]{2}{*}{ Species } & \multicolumn{3}{|c|}{ Chl a } & \multicolumn{3}{|c|}{$C h l b$} & \multicolumn{3}{|c|}{ Chl $a+b$} & \multicolumn{2}{|c|}{ ChlSPAD } \\
\hline & $l$ & $k$ & $R^{2}$ & $l$ & $k$ & $R^{2}$ & $l$ & $k$ & $R^{2}$ & $\min$ & $\max$ \\
\hline winter barley & 0.044 & 4.333 & 0.98 & 0.047 & 1.246 & 0.96 & 0.045 & 5.590 & 0.98 & 6.3 & 64.5 \\
\hline winter wheat & 0.047 & 3.893 & 0.87 & 0.043 & 1.607 & 0.85 & 0.046 & 5.488 & 0.87 & 17.1 & 68.4 \\
\hline spring wheat & 0.041 & 5.811 & 0.93 & 0.041 & 1.971 & 0.91 & 0.041 & 7.783 & 0.93 & 21.1 & 58.6 \\
\hline durum & 0.048 & 3.131 & 0.92 & 0.044 & 1.339 & 0.92 & 0.047 & 4.477 & 0.92 & 18.3 & 67.2 \\
\hline potato & 0.056 & 2.980 & 0.96 & 0.057 & 0.858 & 0.95 & 0.057 & 3.843 & 0.96 & 14.2 & 46.8 \\
\hline sugar beet & 0.039 & 5.205 & 0.88 & 0.034 & 1.526 & 0.93 & 0.040 & 6.771 & 0.91 & 19.1 & 54.0 \\
\hline winter rape & 0.035 & 5.462 & 0.94 & 0.030 & 2.486 & 0.89 & 0.034 & 7.990 & 0.94 & 18.6 & 77.7 \\
\hline
\end{tabular}

\subsubsection{Leaf dry matter and equivalent leaf water}

Leaf dry matter (Leaf dry mat) and equivalent leaf water (Leaf water) are variables of the PROSPECT-5 radiative transfer model (Féret et al., 2008) that is implemented in EO-LDAS. Leaf dry matter is an indicator of cellulose and lignin that absorb shortwave infrared radiation (Baret and Fourty, 1997). The equivalent leaf water exerts an influence on the optical path through the leaf and causes water absorption bands in the wavelength range from 1400 to $2500 \mathrm{~nm}$ (Allen et al., 1969). Leaf dry matter and equivalent leaf water were determined gravimetrically and based on image analysis in 2014. Leaves were collected representatively from the upper, middle, and lower parts of several plants next to SSP00. The leaves were unfurled on a rectangular reference panel $(16 \times 25.5 \mathrm{~cm})$ and pressed flat with a transparent foil, and photos were taken to determine the leaf area (Area). Image analysis included the following steps: removal of artifacts (e.g., shadows, reflections), masking out of areas beyond the reference panel, binarization by assigning a value of 1 to pixels belonging to leaves and a value of 0 to the remaining pixels within the masked area, rectification of the image subset corresponding to the reference panel, extraction of the pixel statistics, and calculation of the leaf area. Image analysis was carried out with R software package "raster" (Hijmans, 2014) and ArcGIS (version 10.2; ESRI, 2013).

After the image acquisition, leaves were put in weighed sealable zip bags and transported to the laboratory. Fresh mass $\left(m_{\text {fresh }}\right)$ was determined on the same day. Afterwards, samples were oven-dried at $52^{\circ} \mathrm{C}$ and dry mass $\left(m_{\text {dry }}\right)$ was ascertained when constant weight was reached. Leaf dry matter (Leaf dry mat) and equivalent leaf water content (Leaf water) were calculated by applying Eqs. (4) and (5) (Baret and Fourty, 1997):

Leaf dry mat $=\frac{m_{\text {dry }}}{\text { Area }}$

and

Leaf water $=\frac{m_{\mathrm{fresh}}-m_{\mathrm{dry}}}{\text { Area } \cdot \rho_{\mathrm{water}}}$, where $\rho_{\text {water }}$ denotes the density of water, which was assumed to be $1 \mathrm{~g} \mathrm{~cm}^{-3}$.

The precision of the Leaf dry mat and Leaf water measurements was examined based on at least two triplicate determinations per investigated cultivar. The $1 \sigma$ errors calculated from the triplicate determinations for Leaf dry mat and Leaf water were $\leq 6 \times 10^{-4} \mathrm{~g} \mathrm{~cm}^{-2}$ and $\leq 21 \times 10^{-4} \mathrm{~cm}$ with associated median values of $1.7 \times 10^{-4} \mathrm{~g} \mathrm{~cm}^{-2}$ and $3.5 \times 10^{-4} \mathrm{~cm}$, respectively.

\subsection{Soil moisture}

In the visible to middle infrared range soil moisture influences the reflectance of the soil surface (Jacquemoud et al., 1992). The mean soil moisture in the uppermost $6 \mathrm{~cm}$ of the topsoil was ascertained in two different ways: (1) gravimetrically based on samples taken with volumetric sampling rings $\left(100 \mathrm{~cm}^{3}\right)$ and $(2)$ with a HH-2 moisture meter equipped with a ThetaProbe type ML2x (Delta-T Devices Ltd.). With both methods, measurements were carried out $\sim 0.5 \mathrm{~m}$ from the ESU diagonal at a SSP in the middle of neighboring planting rows. A high small-scale soil moisture variability is to be expected on potato fields with high values on the furrow bottom and low values on the furrow ridge (Robinson, 1999). Thus, five measurements were performed per examined SSP: one in the middle of the furrow ridge centered between neighboring plants and two additional measurements on each side, i.e., one measurement in the middle of the slope and another one at the bottom of the furrow, respectively.

The gravimetric soil moisture was determined once per ESU on each field working day. At SSP12, a volumetric sampling ring was driven into the soil (five sampling rings on potato fields). Volumetric sampling rings were excavated and the samples were filled into sealable zip bags that were stored in a cooling bag during transport. Wet mass (Wet $\mathrm{m}$ ) was determined on the same day. Afterwards, samples were oven-dried at $105^{\circ} \mathrm{C}$ until a constant weight was reached (Dry $m$ ). Gravimetric soil moisture was calculated relative to the wet mass (wetgrav_SoilMoist). Volumetric soil moisture 
Table 5. Coefficients $p_{x}$ and $q_{x}$ of the linear calibration functions (Eq. 6) for the conversion of the output voltage (Volt_outp, in mV) measured with the ML2x sensor into gravimetric soil moisture (est_wetgrav_SoilMoist, in wt \% relative to the wet mass) and volumetric soil moisture (est_vol_SoilMoist, in \% vol), corresponding coefficients of determination (Pearson's $R^{2}$ ) and root mean square errors (RMSEs), and the range and number $N$ of Volt_outp values involved in the calibration procedure.

\begin{tabular}{lrrrr|rrrrr|r|r}
\hline \multirow{2}{*}{ Field } & \multicolumn{3}{c|}{ est_wetgrav_SoilMoist } & \multicolumn{3}{c|}{ est_vol_SoilMoist } & \multicolumn{3}{c}{ Volt_outp } \\
\cline { 2 - 11 } & $p_{\text {wetgrav }}$ & $q_{\text {wetgrav }}$ & $R^{2}$ & RMSE & $p_{\text {vol }}$ & $q_{\text {vol }}$ & $R^{2}$ & RMSE & min & max & $N$ \\
\hline 340 & 0.0002 & 0.0330 & 0.80 & 1.6 & 0.0004 & 0.0194 & 0.80 & 2.9 & 254 & 790 & 17 \\
350 & 0.0003 & 0.0235 & 0.88 & 1.5 & 0.0005 & 0.0077 & 0.88 & 2.6 & 189 & 802 & 54 \\
430 & 0.0002 & 0.0473 & 0.73 & 1.9 & 0.0003 & 0.0459 & 0.73 & 3.5 & 193 & 875 & 88 \\
440 & 0.0218 & 3.7462 & 0.68 & 2.8 & 0.0379 & 5.0388 & 0.55 & 6.2 & 125 & 878 & 122 \\
470 & 0.0310 & -2.0428 & 0.82 & 2.0 & 0.0562 & -7.3751 & 0.80 & 3.9 & 316 & 756 & 13 \\
500 & 0.0220 & 3.4372 & 0.78 & 2.0 & 0.0401 & 2.2502 & 0.79 & 3.4 & 278 & 858 & 42 \\
771 & 0.0214 & 4.0063 & 0.71 & 2.6 & 0.0385 & 3.8346 & 0.72 & 4.7 & 175 & 872 & 211 \\
820 & 0.0121 & 12.0360 & 0.38 & 2.7 & 0.0237 & 16.9110 & 0.37 & 5.5 & 229 & 775 & 18 \\
830 & 0.0185 & 9.2332 & 0.64 & 2.3 & 0.0369 & 11.1820 & 0.62 & 4.8 & 133 & 897 & 65 \\
\hline
\end{tabular}

(vol_SoilMoist) and the dry bulk density (dBD) of the soil were calculated according to Hartge and Horn (2009). For all fields, a mean dBD of $1.3 \mathrm{~g} \mathrm{~cm}^{-3}$ and a corresponding $95 \%$ confidence level of $0.1 \mathrm{~g} \mathrm{~cm}^{-3}$ were obtained separately from all samples gathered in 2013 and 2014 (Table 5).

Measurements with the HH-2 moisture meter were carried out for each SSP. In 2013, one measurement was conducted per SPP, while in 2014, three measurements were carried out in order to quantify small-scale variability. On potato fields, five readings were taken at each SSP in both years. In the case that acquisitions in the vicinity of dry cracks could not be avoided (Delta-T Devices, 1999), the width of the dry cracks ( $W$ max) was determined. The occurrence of dry cracks implies a higher uncertainty of the measurements (Delta-T Devices, 1999). The ML2x sensor detects an output voltage (Volt_outp) which is subsequently transformed into gravimetric (est_wetgrav_SoilMoist) or volumetric soil moisture (est_vol_SoilMoist). The manufacturer suggests adjusting the (linear) calibration equations for the given soil type (Delta-T Devices, 1999). Hence, the sensor was calibrated separately for each field based on soil moisture values obtained from volumetric sampling rings. The following linear calibration functions (Eq. 6; Table 5) were fitted:

est_X_SoilMoist $=p_{X} \cdot$ Volt outp $+q_{X}$.

$X$ indicates the type of soil moisture (gravimetric or volumetric); i.e., the gain $p_{X}$ and the offset $q_{X}$ were determined separately for est_wetgrav_SoilMoist and est_vol_SoilMoist.

The precision of soil moisture determinations was assessed based on multiple measurements $(N \geq 3)$. The $1 \sigma$ errors for wetgrav_SoilMoist and est_wetgrav_SoilMoist range from 0.14 to $1.92 \mathrm{wt} \%$ and 0.03 to $7.26 \mathrm{wt} \%$ with medians amounting to 0.42 and $0.87 \mathrm{wt} \%$, respectively. The $1 \sigma$ errors for vol_SoilMoist and est_vol_SoilMoist range from 0.25 to $3.52 \%$ vol and 0.01 to $12.90 \%$ vol, while the associated medians are 0.82 and $1.60 \%$ vol, respectively.

\subsection{Hyperspectral characteristic of plants and soil}

Raw digital numbers (DNs) of the surface spectra and the related hemispheric-conical reflectance factors (SchaepmanStrub et al., 2006) were measured with a FieldSpec 3 spectroradiometer (FS3; Analytical Spectral Devices Inc.). Spectra were recorded in the wavelength $(\lambda)$ range from 350 to $1000 \mathrm{~nm}$ and 1001 to $2500 \mathrm{~nm}$ with sampling intervals of 1.4 and $2 \mathrm{~nm}$, respectively (ASD, 2005). Measurements were carried out $1 \mathrm{~m}$ above the top of canopy with an $8^{\circ}$ field of view in the nadir direction. The fiber optic cable connected to the FS3 sensor was mounted on a $1.3 \mathrm{~m}$ long pole. Looking southward, the pole was held horizontally and moved $50^{\circ}$ to the left and right, respectively, while 10 measurements were recorded. Readings were taken successively at all SSPs of an ESU accompanied by the acquisition of reference spectra immediately before and after the target measurements (Milton et al., 2009). The reference spectra were acquired from a Spectralon reference panel (SRT-99-050; Labsphere, Inc.) that was placed on plane-parallel dimensionally stable packing foam (absolute reflectance factors $r<0.045$ for $\lambda \in[350 \mathrm{~nm} / 2500 \mathrm{~nm}])$. During the measurements, the foam was held above the top of canopy, while its horizontal leveling was controlled with a spirit level (T type) placed at the edge of the foam. The comparison of the reference spectra recorded before and after the target measurements gives an indication of the stability of the prevailing atmospheric conditions (ASD, 2005). A description of haze and clouds in the vicinity of the Sun during the hyperspectral measurements is part of the datasets provided at PANGAEA for 2013 (https://doi.org/10.1594/PANGAEA.874243) and 2014 (https://doi.org/10.1594/PANGAEA.874245). Measurements of atmospheric conditions supplement the data (see Sect. 4.5).

Hyperspectral raw data were pre-processed in five steps: 
1. extraction of the acquisition time from the metadata for each hyperspectral measurement;

2. linear interpolation of the DNs acquired over the Spectralon before and after the target measurement runs to get an estimate of the white reference (WR) spectra at the time $(t)$ of each target measurement (Milton et al., 2009). Based on the estimated digital numbers of the white reference $\left(\mathrm{DN}_{\mathrm{estWR}}\right)$, target digital numbers $\left(\mathrm{DN}_{\text {target }}\right)$ were converted into relative reflectance factors $r_{\text {rel }}$ by applying Eq. (7) (Peddle et al., 2001):

$r_{\text {rel }}(\lambda, t)=\frac{\mathrm{DN}_{\text {target }}(\lambda, t)}{\operatorname{DN}_{\text {estWR }}(\lambda, t)} ;$

3. correction of the reflectance factor offset occurring between the FS3 sensors VNIR (350-1000 nm) and SWIR1 (1001-1800 $\mathrm{nm}$ ) by an adjustment of the relative reflectance factors in VNIR ( $\left.r_{\text {rel_VNIR }}\right)$ to the level of SWIR1 relative reflectance factors with Eq. (8):

$$
\begin{aligned}
r_{\text {rel_VNIRcorr }}(\lambda)= & r_{\text {rel_VNIR }}(\lambda)+r_{\text {rel }}(\lambda=1001 \mathrm{~nm}) \\
& -r_{\text {rel }}(\lambda=1000 \mathrm{~nm}) .
\end{aligned}
$$

Relative reflectance factors recorded in the SWIR1 domain were selected as a reference level since the SWIR1 detector shows the smallest temperature-related spectral drift (Hueni and Bialek, 2017);

4. transformation of $r_{\text {rel }}$ into absolute reflectance factors $r$ by multiplication by the reflectance of the Spectralon reference panel (Schaepman-Strub et al., 2006);

5. masking out of reflectance factors in wavelength ranges that were affected by water absorption $(\lambda=1350$ to $1460 \mathrm{~nm}, \lambda=1790$ to $1960 \mathrm{~nm}$; Robinson and MacArthur, 2011) and strong noise $(\lambda=2400$ to $2500 \mathrm{~nm}$ ). Pre-processing was carried out in the R software environment by applying the "prospectr" package (Stevens and Ramirez-Lopez, 2013).

\subsection{Meteorological data and sky conditions}

Data on air temperature, humidity, wind direction, and diffuse solar radiation, among others, were gathered at the Gebesee Fluxnet site (ID: DE-Geb; MPI BGC, 2015). Data access is provided via the European Fluxes Database Cluster (http://gaia.agraria.unitus.it/home). Furthermore, meteorological and climate data (e.g., air temperature, relative humidity, air pressure, precipitation, cloud coverage, wind speed) accompanied by phenological data are recorded at the Dachwig Deutscher Wetterdienst (DWD) station (Fig. 1; station ID: 896; DWD, 2016) that is located about $4 \mathrm{~km}$ west of the Gebesee test site. These data are available via the WebWerdis web portal (https://werdis.dwd.de). Additional data on selected atmospheric and meteorological parameters were collected during the field campaign.

\subsubsection{Solar irradiance, aerosol optical thickness, and column water vapor}

Aerosol optical thickness (AOT) and column water vapor (CWV) characterize the state of the atmosphere and are utilized to correct, for example, influences of aerosol scattering or water absorption on satellite images (Richter and Schläpfer, 2016). In 2014, direct solar irradiance $(E)$, aerosol optical thickness, and column water vapor were derived from measurements with a MICROTOPS II Sunphotometer (model 540; Solar Light Co., Inc.) at wavelengths of $340 \pm 0.3,440 \pm 1.5,675 \pm 1.5,870 \pm 1.5$, and $936 \pm 1.5 \mathrm{~nm}$, respectively (Solar Light, 2007). Additionally, the acquisition time, air mass (Optical airm), and Sun zenith angle (SZA) were recorded. The Sun photometer was operated using the manufacturer's calibration constants delivered with the instrument in January 2014. The quartz window in front of the sensors was cleaned before each field measurement day to avoid measurement errors (Ichoku et al., 2002) and the Sun photometer was mounted on a tripod to enable accurate pointing to the Sun (Morys et al., 2001). One reading per ESU was taken, either at SSP00 or at SSP24. All measurements were annotated with descriptions of haze and cloud cover.

\subsubsection{Sky conditions}

Cloud coverage and photos of the sky condition are indicators of the prevailing illumination conditions and thus relevant metadata for the hyperspectral data acquired with the FieldSpec 3 spectroradiometer (Pfitzner et al., 2006). Overall cloud coverage (Cloud cov) expressed in oktas was assessed visually and documented once per ESU. In addition, photos were taken at SSP00 to depict the condition of the sky around the zenith and close to the horizon in the direction of SSP24 (i.e., NNE). The photos acquired in 2013 (https://doi.org/10.1594/PANGAEA.874250) and 2014 (https://doi.org/10.1594/PANGAEA.874697) can be accessed at PANGAEA. Descriptions of the haze and cloud cover close to the Sun during the spectrometer (Sect. 4.4) and Sun photometer (Sect. 4.5.1) measurements were added as an annotation to the corresponding parameters.

\subsection{Further investigations}

\subsubsection{Landscape photos}

Landscape photos were taken at SSP00 oriented parallel and orthogonal to the direction of the planting rows and toward SSP24, respectively. The photos depict the condition of the vegetation on the ESU and its surroundings and are available at PANGAEA for 2013 (https://doi.org/10.1594/PANGAEA.874700) and 2014 (https://doi.org/10.1594/PANGAEA.874703). 


\subsubsection{Surveying of ESUs, ground control points, and checkpoints}

Comparison between space-borne and ground reference data requires a solid foundation for the geo-referencing of satellite images. Thus, coordinates and heights above the ellipsoid (HAE) were recorded at SSP00 and SSP24 of all ESUs using differential global navigation satellite systems (dGNSS). In addition, 15 ground control points (GCPs) and 20 checkpoints (CPs) in the vicinity of the Gebesee test site were surveyed. GCPs were selected in accordance with the guidelines of Kapnias et al. (2008) and considering the requirements of PCI Geomatics (2009) for the orthorectification of satellite images with the rational functions math model. CPs were placed between the GCPs, following the recommendations of Kapnias et al. (2008). All points were located on straight road segments, most of them on road junctions. Supporting information for the localization of survey points in satellite images (e.g., the width of the roads) and photos showing the setting of the GCPs is provided at PANGAEA (https://doi.org/10.1594/PANGAEA.874247).

GCPs and positions of ESUs investigated in 2013 were surveyed with a LEICA GS15 rover. Measurements at each survey point were integrated over 2 min to obtain mean values from 120 position readings ( 2 readings per second). Data post-processing was carried out with the Leica Geo Office 8.3 software (LEICA Geosystems, 2012). A virtual reference station (VRS; $51^{\circ} 05^{\prime} \mathrm{N}, 10^{\circ} 56^{\prime} \mathrm{E}$ ) was generated based on the SAPOS Thuringia network of continuously operating GNSS base stations (AdV, 2013). The differential calculation of the coordinates referred to this VRS, with a maximum distance between survey points and VRS of $8.1 \mathrm{~km}$.

CPs and ESUs investigated in 2014 were surveyed with a STONEX S9IIIN rover which was operated in real-time kinematic (RTK) mode connected to the SAPOS base stations. The maximum distance between survey points and the nearest SAPOS base station (reference station Erfurt; TLVermGeo, 2016) was $15.4 \mathrm{~km}$.

The mean positional precision ( $1 \sigma$ error) in the horizontal direction (2-D) is $<0.01 \mathrm{~m}$ in 2013 and 2014. The precision of the HAE is $<0.01$ and $0.01 \mathrm{~m}$ in 2013 and 2014, respectively. In 2014, repeated triplicate position determinations were carried out on different days for most of the survey points to allow for an estimation of uncertainties introduced by the placement of the rover and changing satellite constellations. The resulting $1 \sigma$ error is $\leq 0.05$ and $\leq 0.03 \mathrm{~m}$ in the horizontal and vertical directions, respectively.

HAEs were transformed into physical heights (Altitude) referring to the German state height reference system (DHHN92) based on bi-cubic spline interpolation between data points provided with the German Combined QuasiGeoid 2011 grid (GCG2011; BKG, 2011). GCG2011 data and the software for the interpolation (gintbs.exe) and conversion (geoid.exe) were kindly provided by the Federal Agency for Cartography and Geodesy (BKG).

\section{Results}

\subsection{Synchronization of in situ measurements and satellite acquisitions}

Archives accessible via USGS Earth Explorer, ESA EOLi, and RESA EyeFind host 11 satellite images of the Gebesee test site with zero or low $(<25 \%)$ cloud coverage that were acquired by the sensors of Landsat-7, -8, SPOT 5, and RapidEye in 2013. For 10 of these acquisitions, in situ data were collected less than 1 day apart. In seven cases ground reference data were gathered on the same day (Fig. 3). Among the 11 satellite images, 7 are cloud free, while certain ESUs are covered by haze and clouds on the remaining images. For 2014, 21 satellite images are available showing the Gebesee test site with zero or low cloud coverage. The number of satellite images acquired no more than 1 day before or after the collection of the in situ data is 15 . In total, seven of the images were acquired on a day of field work (Fig. 3). Moreover, 11 of the 21 images are cloud free.

\subsection{Interannual and spatial variability}

Meteorological conditions at the Gebesee test site differed considerably between 2013 and 2014. This becomes apparent in the evolution of the investigated parameters. In Fig. 4, time series of soil moisture, plant height, and proportion of senescent material on ESUs cultivated with spring wheat cultivar Taifun are compared with mean monthly temperature and monthly rainfall. Compared to mean values of long-term time series recorded at the Dachwig DWD station (1991-2014), the beginning of the year 2013 was characterized by abnormally long-lasting low temperatures (Fig. 4a). Only starting from 9 April did the daily mean air temperature persistently exceed the mean daily temperature of $3.5^{\circ} \mathrm{C}$ required for sowing and emergence of wheat (Porter and Gawith, 1999; DWD, 2015). On the same day, spring wheat was drilled on acreage 430 and 1 day later on acreage 830. In contrast, spring wheat was drilled on 13 February on acreage 350 in 2014, when the temperature was already sufficiently high. Mean temperatures from February to April 2014 range among the highest values measured between 1991 and 2014 in the corresponding months (DWD, 2015). As a consequence, plant growth in 2014 is more than 3 weeks in advance compared to 2013 until the end of rapid plant growth in the early summer (Fig. 4c). Synchronously, the emergence of inflorescence (BBCHkey: 59) was completed on 19 and 26 June 2013 and 1 June 2014 at ESU 430-2, 830-3, and $350-1$, respectively.

The first half of 2014, except May, was characterized by monthly precipitations close to the long-term minimum (Fig. 4a). Until June, monthly precipitation was higher in 2013 compared to 2014 and entails a higher soil moisture content in 2013 (Fig. 4b). Increasing temperature which causes rising evapotranspiration rates in combination with 

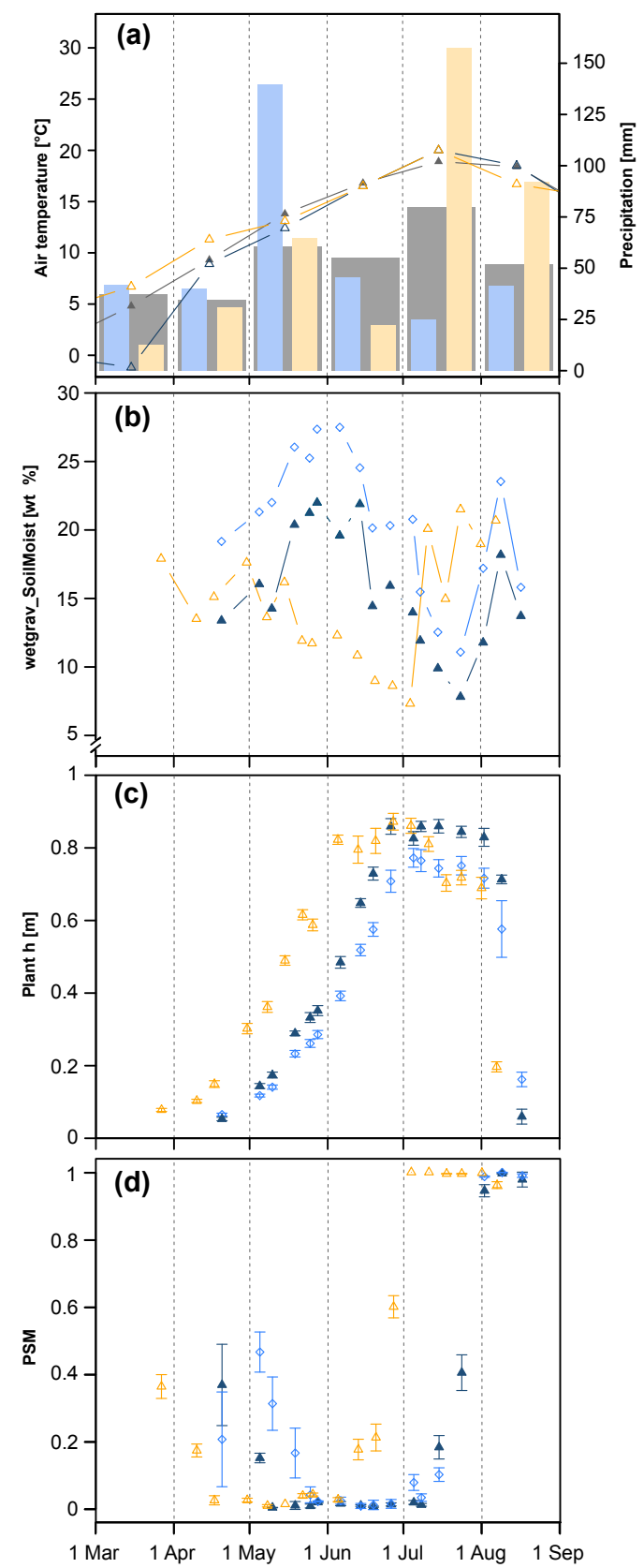

\begin{tabular}{|cc|}
\hline Cultivation period & Soil type \\
2013 & $\Delta$ Haplic chernozem (mean) \\
2014 & $\diamond \quad$ Vertic chernozem (mean) \\
$1991-2014$ & I $95 \%$ confidence interval \\
\hline
\end{tabular}

Figure 4. Comparison of meteorological conditions, soil moisture, and vegetation parameters characterizing spring wheat (cultivar: Taifun) in 2013 and 2014: (a) monthly mean air temperature and monthly rainfall; (b) gravimetric soil moisture (wetgrav_SoilMoist); (c) plant height (Plant $h$ ); and (d) proportion of senescent material (PSM). Air temperature and rainfall were recorded at the Dachwig meteorological station (DWD, 2015). low precipitation led to an early decrease in the soil moisture content in 2014 (Fig. 4a, b). Senescence appeared about 1 month earlier in 2014 compared to 2013 (Fig. 4d). In 2014, progressing senescence and the last (slower) phase of plant growth coincided, while plants were still green during this phase in 2013 (Fig. 4c, d). The slow growing phase lasted 1 week in 2013 until maximum plant height was reached, while it took 3 weeks in 2014 (Fig. 4c). After greenness was gone, ears started to droop, which led to a decrease in plant height (Fig. 4c, d). This decrease indicated finalization of ear ripening (BBCH principal growing stage: 9) and appeared 3 weeks later in 2013 compared to 2014 . High monthly precipitation in July and August 2014 delayed the harvest until 2 August. Compared to the harvest in 2013 on acreages 430 and 830, it took place only 10 and 13 days in advance, respectively.

Spatial variability is, for example, documented in the evolution of parameters characterizing the growth of spring wheat on acreage 430 and 830 in 2013. Soil moisture content on ESU 430-2 is 2 to $8 \mathrm{wt} \%$ lower than on ESU 830-3 (Fig. 4b). Nevertheless, plants on ESU 430-2 grow faster and reach a mean maximum plant height that is $0.1 \mathrm{~m}$ higher than on ESU 830-3 (Fig. 4c). On both ESUs senescence starts synchronously, but greenness vanishes about 1 week earlier at ESU 830-3 (Fig. 4d). Due to the proximity of the acreages meteorological conditions can be assumed identical. Instead, the observed differences might be partially attributable to varying soil fertility. This can be explained by artificial manure, but may be also due to differing soil types. Acreage 430 is characterized by rather fertile Haplic Chernozems promoting plant growth (Zech et al., 2014), while acreage 830 is characterized by Vertic Chernozems with an elevated clay content that confines the amount of plant-available soil water and may lead to an earlier senescence (Blume et al., 2016). However, the data indicate that interannual variability caused larger differences with respect to the investigated parameters than prevailing heterogeneity in pedological conditions (Fig. 4b-d).

\subsection{Influence of vegetation parameters on hyperspectral reflectance factors and their variability between crop types}

The simultaneous acquisition of in situ data and hyperspectral measurements permits the examination of relationships between plant physiological states and the surface reflectance factors that are expected to vary between different phenological stages and crop types (e.g., Haboudane et al., 2004). This is exemplified for winter rape, winter wheat, and potato that belong to the plagiophile, erectophile, and planophile leaf angle distribution (LAD) classes defined by de Wit (1965) and Eagelson (2004), respectively, and are representatives of all LAD classes sampled during the field campaigns.

Figure 5 shows nadir photos as well as mean values with $95 \%$ confidence intervals of selected vegetation parameters 
(a)
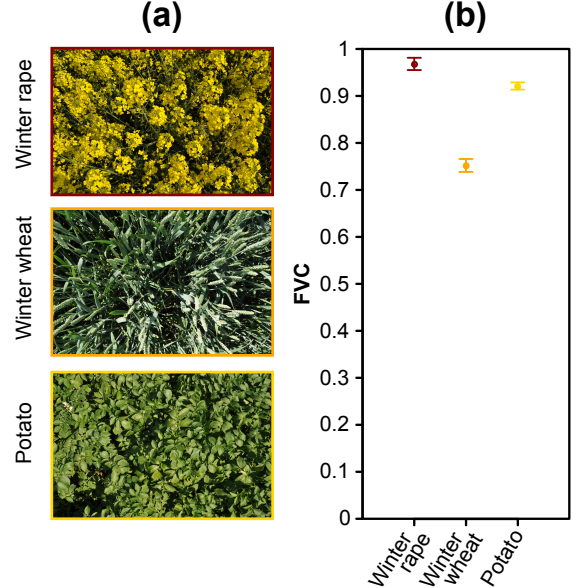

(c)

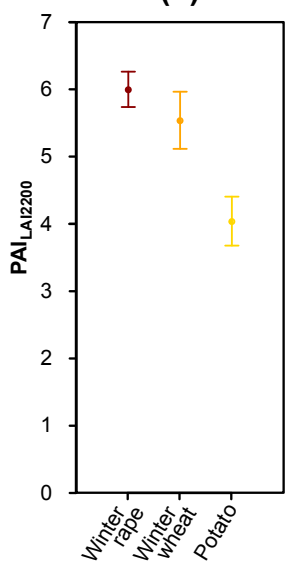

(d)

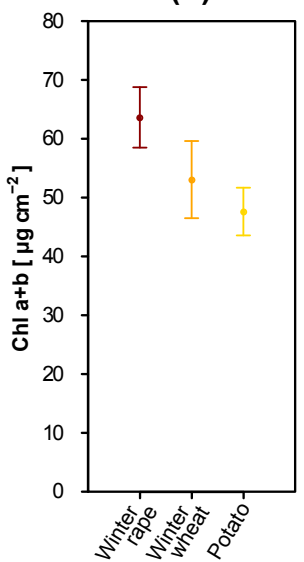

(f)

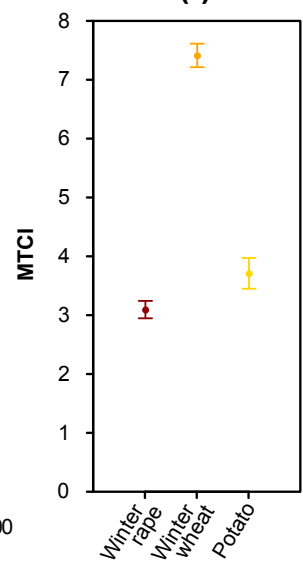

Figure 5. Differences in parameter characteristics, illustrated for fractional vegetation cover (FVC), plant area index (PAI $\mathrm{LAI}_{2200}$ ), leaf chlorophyll $a$ and $b$ content ( $C h l a+b)$, averaged absolute canopy reflectance factors, and the MERIS Terrestrial Chlorophyll Index (MTCI) following Dash and Curran (2004) for crops with varying leaf angle distributions (LADs) in similar phenological stages (BBCHkeys: winter rape: 65-67; winter wheat: 69; potato: 69-70). Average values and the corresponding $95 \%$ confidence intervals were determined from measurements that were carried out on an elementary sampling unit (ESU), respectively. Uncertainties of mean spectra (95\% confidence intervals; not shown to maintain clarity of the figure) are $<0.04$ for winter rape and winter wheat and $<0.11$ for potato. Wavelengths that are involved in the calculation of the MTCI are indicated with vertical dashed lines in Fig. 5e.

and absolute reflectance factors $r$ from which the MERIS Terrestrial Chlorophyll Index (MTCI) following Dash and Curran (2004) was calculated (Eq. 9).

$\mathrm{MTCI}=\frac{r(\lambda=754 \mathrm{~nm})-r(\lambda=709 \mathrm{~nm})}{r(\lambda=709 \mathrm{~nm})-r(\lambda=681 \mathrm{~nm})}$

The data characterize the three crop types in a comparable phenological state, i.e., at the end of the flowering stage in 2014. Winter rape already reached the stage of declining flowering (BBCHkey: 65-67) on 30 April 2014, while the end of flowering of winter wheat (BBCHkey: 69) and potato (BBCHkey: 69-70) was only observed on 6 June and 4 July 2014 , respectively.

The FVC that was derived from nadir photos (Fig. 5a, b) is $97 \pm 1,75 \pm 1$, and $92 \pm 1 \%$ for winter rape, winter wheat, and potato, respectively, with the proportion of senescent ma- terial (PSM) being $<5 \%$ for all three crop types. The highest mean PAI LAI2200 (Fig. 5c) was determined for winter rape and amounts to $6.0 \pm 0.3$. The mean PAI LAI2200 of winter wheat $(5.5 \pm 0.4)$ is higher than for potato $(4.0 \pm 0.4)$, despite the lower FVC. Similarly, Chl $a+b$ (Fig. 5d) is highest for winter rape $\left(64 \pm 5 \mu \mathrm{g} \mathrm{cm}^{-2}\right)$, followed by winter wheat $\left(53 \pm 7 \mu \mathrm{g} \mathrm{cm}^{-2}\right)$ and potato $\left(48 \pm 4 \mu \mathrm{g} \mathrm{cm}^{-2}\right)$.

The corresponding absolute canopy reflectance factors (350-2400 nm; Fig. 5e) of winter rape and potato are rather similar, with a mean deviation of 0.037 . The absolute reflectance factors of winter wheat are generally lower and deviate by 0.076 and 0.071 on average from the absolute reflectance factors of winter rape and potato, respectively. Notably, illumination conditions were similar during the acquisition of the hyperspectral data, with SZAs ranging from 44 to $46^{\circ}$. Hence, correction for illumination conditions is ex- 
pendable in this example. Figure $5 \mathrm{f}$ depicts the MTCI that is expected to increase linearly with increasing $C h l a+b$ (Liang et al., 2016). However, the MTCI for winter rape $(3.0 \pm 0.3)$ is lower than for winter wheat $(7.4 \pm 0.3)$ and potato $(3.5 \pm 0.01)$, which is in contrast to the $C h l a+b$ values.

The lower FVC of winter wheat as compared to potato (Fig. 5b) which seems counterintuitive given the higher mean

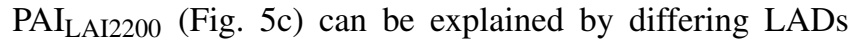
(Weiss et al., 2004). At the end of the flowering stage the leaf development and stem elongation of winter rape, winter wheat, and potato are completed (Meier, 2001). The crops cover the space between the planting rows and the FVC is close to the species-specific maximum value. The canopy of winter wheat is mainly characterized by vertically oriented leaves (erectophile LAD). From the nadir perspective, only a small proportion of the leaf area contributes to the coverage of the soil. In contrast, potato leaves are almost horizontally oriented (planophile LAD), which leads to a large coverage despite a smaller leaf area. PAI and LAD exert influence on the leaf area that interacts with solar radiation and, thus, the reflectance factors in the wavelength range from 400 to $2500 \mathrm{~nm}$ (Mousivand et al., 2014). Therefore, the combination of PAI and LAD might explain the lower absolute reflectance factors of winter wheat as compared to winter rape and potato (Fig. 5e).

In the wavelength range from 400 to $700 \mathrm{~nm}$ the absorption of blue and red light increases proportionally with $C h l a+b$ (Lichtenthaler and Buschmann, 2001). Considering measured $C h l a+b$, the highest absorption would be expected for winter rape, but the leaves are partially covered by yellow petals. In addition, these petals increase the reflectance factors between 500 and $2500 \mathrm{~nm}$ (Lilienthal and Schnug, 2005). The flavonol with the glycoside component Isorhamnetin 3-glucoside causes the yellow color of the petals (Harborne, 1967; Haneklaus et al., 2005) which is particularly evident between 500 and $700 \mathrm{~nm}$ (Fig. 5e). While the MTCI has proven to be valuable for the determination of the $C h l a+b$ from hyperspectral canopy reflectance factors under diverse phenological conditions (Liang et al., 2016), the index is compromised by the occurrence of yellow petals (Fig. 5d, f).

The current example illustrates that the database can be utilized to link changes in spectral characteristics over the cultivation period to processes that are manifested in vegetation parameters. Interrelations between the absolute surface reflectance factors and vegetation parameters can be assessed for various crop types with differing canopy architectures. Therefore, the database can contribute to the development, validation, and enhancement of empirical and processbased models for the derivation of plant physiological states of crops.

\section{Data availability}

The database described in this paper is archived at PANGAEA (https://doi.org/10.1594/PANGAEA.874251, Truckenbrodt and Baade, 2017) and comprises 13 datasets. An overview of all available parameters, hyperlinks to the corresponding datasets, and a short parameter characterization are provided in the file "Description of investigated parameters". Metadata on the investigated fields and crop types are summarized in the file "Metadata on the cultivars and investigated fields" that supplements the database.

\section{Conclusions}

This paper introduces a comprehensive and freely available ground reference database on the phenological evolution of seven crop types cultivated on the Gebesee test site in 2013 and 2014. A detailed description of the measurement design and data acquisition is provided. The uniqueness of the database is the high number of investigated vegetation parameters that influence the surface reflectance in the visible and infrared range and their simultaneous assessment for crops with various canopy architectures in conjunction with the high temporal resolution of the data acquisition. The land surface was investigated regarding soil moisture, biophysical plant parameters, and leaf structural and biochemical parameters. Data collection was accompanied by hyperspectral measurements of surface reflectance factors and characterization of atmospheric states. Ground reference and spaceborne data (RapidEye, SPOT 5, Landsat-7 and -8) acquired less than 1 day apart and with $\leq 25 \%$ of the test site being cloud covered are available for 10 and 15 days in 2013 and 2014, respectively.

The database provides, in general, a solid foundation for the set-up, validation, and enhancement of empirically and physically based models and remote sensing applications targeting crop monitoring. Parameters and spectral properties of various crop types can be compared by considering variations in space and time. Spatial variability is documented on the scale of SSPs and ESUs, and for selected crops within and between acreages. Interannual variability arises from distinct meteorological conditions in 2013 and 2014. The Gebesee test site is particularly suited for the acquisition of ground reference data. It is representative of cultivated areas in the mid-latitudes of central Europe. Due to its low relief energy (slope inclination $<5 \%$ ) and comparably large acreages ( 8.57 to $60.49 \mathrm{ha}$ ) it is convenient for the validation of remote sensing products. Since 1991 temperature, relative humidity, air pressure, cloud coverage, and wind speed have been recorded at the Dachwig DWD station, while rainfall records extend back to the 1960s (DWD, 2016). Combining the current database with ongoing measurements of $\mathrm{CO}_{2}$ and water vapor exchange at the Gebesee flux tower that started in 2001 (MPI BGC, 2015) opens up opportunities to test and validate soil-vegetation-atmosphere transfer (SVAT), surface- 
energy-balance (SEB) models, and satellite-aided retrieval models. The database will be used to implement realistic prior information in EO-LDAS and to assess the effects on the accuracy of derived vegetation parameter values. 
Appendix A: Alphabetical list of acronyms used in this study

\begin{tabular}{|c|c|}
\hline Acronym & Description \\
\hline $\mathrm{ACF}$ & apparent clumping factor \\
\hline AGB & above-ground biomass \\
\hline AgriSAR 2006 & a ground and airborne campaign carried out on the DEMMIN test site, Germany, in 2006 \\
\hline AgriSAR 2009 & $\begin{array}{l}\text { a ground and airborne campaign carried out on the Barrax test site, Spain, in Flevoland, } \\
\text { the Netherlands, and in Indian Head, Canada, in } 2009\end{array}$ \\
\hline AOT & aerosol optical thickness \\
\hline AquiferEx & field campaign of the Aquifer project (carried out in southern Tunisia in 2005) \\
\hline Area & area of leaves sampled for the determination of Leaf dry mat and Leaf water \\
\hline Awn l & awn length \\
\hline $\mathrm{BBCH}$ & $\begin{array}{l}\text { Biologische Bundesanstalt für Land- und Forstwirtschaft, Bundessortenamt } \\
\text { und CHemische Industrie }\end{array}$ \\
\hline BBCHkey & growing stage key according to the extended $\mathrm{BBCH}$ scale \\
\hline BigFoot & $\begin{array}{l}\text { ground validation project conducted in North and South America to provide data on multiple } \\
\text { scales for the MODIS Land Discipline Group from } 2000 \text { to } 2003\end{array}$ \\
\hline Biom above gr/acreage & harvested AGB (data provided by Geratal Agrar) \\
\hline BKG & $\begin{array}{l}\text { Bundesamt für Kartographie und Geodäsie (Federal Agency for Cartography } \\
\text { and Geodesy, Germany) }\end{array}$ \\
\hline CEFLES2 & $\begin{array}{l}\text { CarboEurope FLEX (Fluorescence Explorer) Sentinel-2 (a ground and airborne campaign } \\
\text { carried out in southwest France in 2007) }\end{array}$ \\
\hline Chl a & content of leaf chlorophyll $a$ \\
\hline Chl $a+b$ & content of leaf chlorophyll $a$ and $b$ \\
\hline$C h l b$ & content of leaf chlorophyll $b$ \\
\hline Chl X & representation for Chl $a, C h l b$ or $C h l a+b$ (X can be $a, b$ or $a+b$; see Eq. 3$)$ \\
\hline ChlSPAD & relative amount of leaf chlorophyll determined with the SPAD502Plus \\
\hline Cloud cov & overall cloud coverage \\
\hline $\mathrm{CP}$ & checkpoint \\
\hline CWV & column water vapor \\
\hline $\mathrm{dBD}$ & dry bulk density \\
\hline dGNSS & differential Global Navigation Satellite System \\
\hline DHHN92 & Deutsches Haupthöhennetz 1992 (German state height reference system) \\
\hline DHP & digital hemispherical photo \\
\hline $\mathrm{DN}$ & digital number \\
\hline $\mathrm{DN}_{\mathrm{estWR}}$ & estimated digital numbers of the white reference \\
\hline $\mathrm{DN}_{\text {target }}$ & digital numbers of the target \\
\hline Dry m & Dry mass of soil sample \\
\hline DWD & Deutscher Wetterdienst \\
\hline$E$ & direct solar irradiance \\
\hline EnMAP & $\begin{array}{l}\text { German Environmental Mapping and Analysis Program (a ground and hyperspectral airborne } \\
\text { campaign carried out on different test sites in Germany from } 2009 \text { to 2015) }\end{array}$ \\
\hline EO-LDAS & Earth Observation Land Data Assimilation System \\
\hline EOS & Earth Observing System \\
\hline ESA EOLi & European Space Agency Earth Observation Link \\
\hline est_vol_SoilMoist & estimated vol_SoilMoist, i.e., the linear transformed Volt_outp \\
\hline est_wetgrav_SoilMoist & estimated wetgrav_SoilMoist, i.e., the linear transformed Volt_outp \\
\hline est_X_SoilMoist & $\begin{array}{l}\text { representation for } \text { est_wetgrav_SoilMoist and est_vol_SoilMoist } \\
(X \text { can be gravimetric or volumetric; see Eq. } 6)\end{array}$ \\
\hline ESU & elementary sampling unit \\
\hline ETM+ & Enhanced Thematic Mapper Plus (sensor carried by Landsat-7) \\
\hline
\end{tabular}




\begin{tabular}{|c|c|}
\hline FoS & fraction of sky \\
\hline FOV & field of view \\
\hline Fr yield/acreage & fruit yields (data provided by Geratal Agrar) \\
\hline FS3 & FieldSpec 3 spectroradiometer \\
\hline FVC & fractional vegetation cover \\
\hline GCG2011 & German Combined QuasiGeoid 2011 \\
\hline GCP & ground control point \\
\hline Geratal Agrar & Geratal Agrar GmbH \& Co. KG Andisleben \\
\hline GNSS & Global Navigation Satellite System \\
\hline $\mathrm{H}$ & hue \\
\hline HAE & height above ellipsoid \\
\hline HRG & High Resolution Geometric (sensor carried by SPOT 5) \\
\hline HSL & hue, saturation, lightness (color space) \\
\hline HYFLEX & $\begin{array}{l}\text { HYperspectral FLuorescence EXperiment (a ground and hyperspectral airborne campaign carried } \\
\text { out in the Ruhr catchment, Germany, in 2012) }\end{array}$ \\
\hline Incl & ear inclination \\
\hline JECAM & Joint Experiment of Crop Assessment and Monitoring \\
\hline$k$ & ordinate intercept of the exponential function applied to determine $C h l X$ (see Eq. 3 ) \\
\hline $\mathrm{L}$ & lightness \\
\hline$l$ & relative rate of change of the exponential function applied to determine $C h l X$ (see Eq. 3) \\
\hline LAD & leaf angle distribution \\
\hline LAI & leaf area index \\
\hline LAI-2200 & LAI-2200 Plant Canopy Analyzer (LI-COR Biosciences, Inc.) \\
\hline Leaf dry mat & leaf dry matter \\
\hline Leaf water & equivalent leaf water \\
\hline LS7 & Landsat-7 ETM+ \\
\hline LS8 & Landsat-8 OLI \\
\hline$m$ & 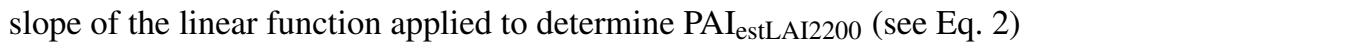 \\
\hline $\max$ & maximum of calibration range \\
\hline$m_{\text {dry }}$ & dry mass of leaves sampled for the determination of Leaf dry mat and Leaf water \\
\hline$m_{\text {fresh }}$ & fresh mass of leaves sampled for the determination of Leaf dry mat and Leaf water \\
\hline $\min$ & minimum of calibration range \\
\hline MTCI & Medium Resolution Imaging Spectrometer (MERIS) Terrestrial Chlorophyll Index \\
\hline$n$ & 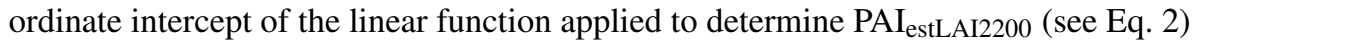 \\
\hline NASA & National Aeronautics and Space Administration \\
\hline$n \operatorname{Class}_{X}$ & $\begin{array}{l}\text { number of pixels ascribed to class } X \text { by means of an automatic classification } \\
\text { ( } X=\text { FVC represents "vegetation" and } X=\text { PSM represents "senescent vegetation") }\end{array}$ \\
\hline$n R e f_{\text {all }}$ & $\begin{array}{l}\text { number of pixels involved in the validation of the classification of } \\
\text { "vegetation" and "senescent vegetation" }\end{array}$ \\
\hline$n \operatorname{Re} f_{X}$ & number of pixels ascribed to class $X$ by means of a visual inspection \\
\hline & ( $X=$ FVC represents "vegetation" and $X=$ PSM represents "senescent vegetation") \\
\hline OLI & Operational Land Imager (sensor carried by Landsat-8) \\
\hline Optical airm & air mass \\
\hline PAI & plant area index \\
\hline PAI CanEye & "true" PAI determined from DHPs with the CAN-EYE V6.313 software \\
\hline PAI estLAI2200 $_{2}$ & estimated PAI $\mathrm{LAI}_{2200}$, i.e., the linear transformed PAI $\mathrm{I}_{\text {anEye }}$ (see Eq. 2) \\
\hline $\mathrm{PAI}_{\mathrm{LAI} 2200}$ & "true" PAI measured with LAI-2200 \\
\hline Plant $h$ & plant height \\
\hline PSM & proportion of senescent material \\
\hline$p_{\mathrm{vol}}$ & gain, i.e., the slope of the linear function applied to determine est_vol_SoilMoist (see Eq. 6) \\
\hline$p_{\text {wetgrav }}$ & gain, i.e., the slope of the linear function applied to determine est_wetgrav_SoilMoist (see Eq. 6) \\
\hline$p_{X}$ & gain, i.e., the slope of the linear function applied to determine est_X_SoilMoist (see Eq. 6) \\
\hline
\end{tabular}




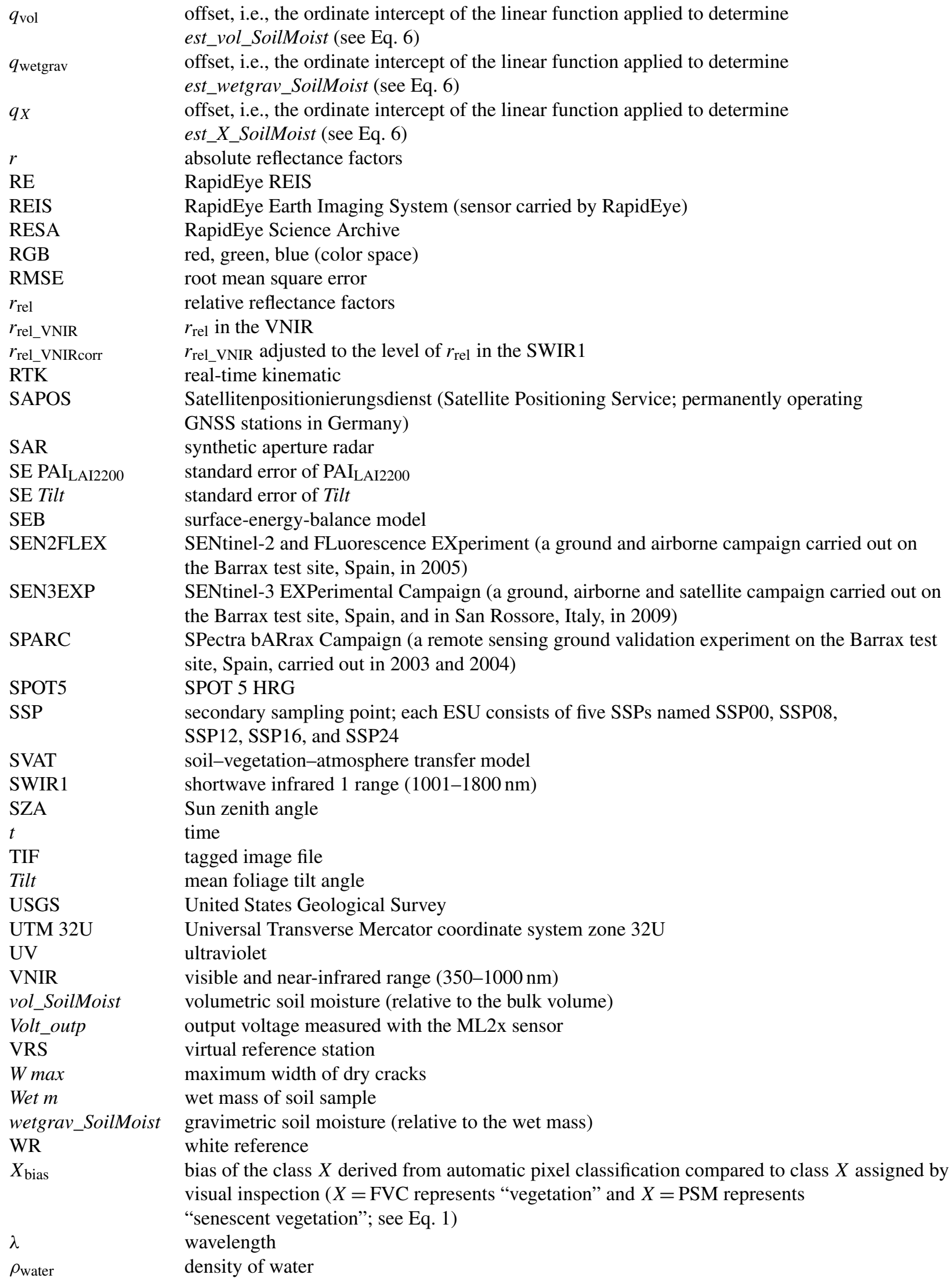

$q_{\mathrm{vol}}$

$q_{\text {wetgrav }}$

$q_{X}$

$r$

RE

REIS

RESA

RGB

RMSE

$r_{\text {rel }}$

$r_{\text {rel_VNIR }}$

$r_{\text {rel_VNIRcorr }}$

RTK

SAPOS

SAR

SE PAI LAI2200

SE Tilt

SEB

SEN2FLEX

SEN3EXP

SPARC

SPOT5

SSP

SVAT

SWIR1

SZA

$t$

TIF

Tilt

USGS

UTM 32U

UV

VNIR

vol_SoilMoist

Volt_outp

VRS

$W \max$

Wet $m$

wetgrav_SoilMoist

WR

$X_{\text {bias }}$

$\lambda$

$\rho_{\text {water }}$

offset, i.e., the ordinate intercept of the linear function applied to determine

est_vol_SoilMoist (see Eq. 6)

offset, i.e., the ordinate intercept of the linear function applied to determine

est_wetgrav_SoilMoist (see Eq. 6)

offset, i.e., the ordinate intercept of the linear function applied to determine

est_X_SoilMoist (see Eq. 6)

absolute reflectance factors

RapidEye REIS

RapidEye Earth Imaging System (sensor carried by RapidEye)

RapidEye Science Archive

red, green, blue (color space)

root mean square error

relative reflectance factors

$r_{\text {rel }}$ in the VNIR

$r_{\text {rel_VNIR }}$ adjusted to the level of $r_{\text {rel }}$ in the SWIR1

real-time kinematic

Satellitenpositionierungsdienst (Satellite Positioning Service; permanently operating

GNSS stations in Germany)

synthetic aperture radar

standard error of PAI LAI2200

standard error of Tilt

surface-energy-balance model

SENtinel-2 and FLuorescence EXperiment (a ground and airborne campaign carried out on the Barrax test site, Spain, in 2005)

SENtinel-3 EXPerimental Campaign (a ground, airborne and satellite campaign carried out on the Barrax test site, Spain, and in San Rossore, Italy, in 2009)

SPectra bARrax Campaign (a remote sensing ground validation experiment on the Barrax test site, Spain, carried out in 2003 and 2004)

SPOT 5 HRG

secondary sampling point; each ESU consists of five SSPs named SSP00, SSP08,

SSP12, SSP16, and SSP24

soil-vegetation-atmosphere transfer model

shortwave infrared 1 range (1001-1800 nm)

Sun zenith angle

time

tagged image file

mean foliage tilt angle

United States Geological Survey

Universal Transverse Mercator coordinate system zone 32U

ultraviolet

visible and near-infrared range (350-1000 nm)

volumetric soil moisture (relative to the bulk volume)

output voltage measured with the ML2x sensor

virtual reference station

maximum width of dry cracks

wet mass of soil sample

gravimetric soil moisture (relative to the wet mass)

white reference

bias of the class $X$ derived from automatic pixel classification compared to class $X$ assigned by visual inspection ( $X=\mathrm{FVC}$ represents "vegetation" and $X=\mathrm{PSM}$ represents

"senescent vegetation"; see Eq. 1)

wavelength

density of water 
Author contributions. ST set up the experimental design of the field campaigns. She was in charge of the accomplishment of field work and the maintenance of the equipment. Moreover, she was involved in all field work and is responsible for the data processing.

CS played a supervisory role and contributed to the development of the field campaign design.

The manuscript was written by ST with contributions from CS.

Competing interests. The authors declare that they have no conflict of interest.

Acknowledgements. The authors would like to thank Matthias Döring, René Döring and Corina Geyer for providing access to in-house data and permitting research activities on the fields of the Geratal Agrar GmbH \& Co. KG Andisleben. We sincerely thank Jussi Baade for acquiring and post-processing dGNSS data in 2013. We would like to express our gratitude to Matthias Hirth and Severin Sasso for enabling chlorophyll measurements at the laboratory facilities of the Institute of General Botany and Plant Physiology. We cordially thank Beate Michalzik for the assistance in determining soil types. José Gómez-Dans, Dietrich Feist, Sören Hese and Nuno Carvalhais are sincerely thanked for fruitful discussions. Moreover, we acknowledge Matthias Forkel, Andreas Hueni and two anonymous reviewers for constructive comments on an earlier version of the manuscript. We are greatly indebted to the numerous field and laboratory helpers that contributed to the accomplishment of the database. The Federal Agency for Cartography and Geodesy is thanked for free provision of GCG2011 data and processing software (gintbs.exe, geoid.exe). Cloud coverage was determined from RapidEye data that has been contributed on behalf of the German Aerospace Center through funding of the German Federal Ministry of Economy and Energy. SPOT 5 and Landsat data were kindly provided by the European Space Agency and the US Geological Survey, respectively. Funding by the German Federal Ministry of Economic Affairs and Energy via the research project "Application of the EO-LDAS Prototype and Database to Prepare Sentinel-2 Assimilation" (grant: 50EE1307) is gratefully acknowledged.

Edited by: David Carlson

Reviewed by: two anonymous referees

\section{References}

AdV (Arbeitsgemeinschaft der Vermessungsverwaltungen der Länder der Bundesrepublik Deutschland): SAPOS - Satellite Positioning Service of the German National Survey, available at: http://www.adv-online.de/Spatial-Reference/SAPOS/ (last access: 31 August 2016), 2013.

Allen, W. A., Gausman, H. W., Richardson, A. J., and Thomas, J. R.: Interaction of Isotropic Light with a Compact Plant Leaf, J. Opt. Soc. Am., 59, 1376-1379, https://doi.org/10.1364/JOSA.59.001376, 1969.

Anthoni, P. M., Freibauer, A., Kolle, O., and Schulze, E.-D.: Winter wheat carbon exchange in Thuringia, Germany, Agr.
Forest Meteorol., 121, 55-67, https://doi.org/10.1016/S01681923(03)00162-X, 2004.

ASD (Analytical Spectral Devices): FieldSpec 3 User Manual, ASD-Document 600510 Rev. C, ASD Inc., Boulder, USA, 90 pp., 2005.

Baret, F.: A simple method to calibrate hemispherical photographs, available at: http://w3.avignon.inra.fr/valeri/fic_htm/ methodology/main.php, last access: 16 October 2014, 2004.

Baret, F. and Fourty, T.: Estimation of leaf water content and specific leaf weight from reflectance and transmittance measurements, Agronomie, 17, 455-464, https://doi.org/10.1051/agro:19970903, 1997.

Bauer, L.: Thüringer Becken und Randplatten, in: Handbuch der Naturräumlichen Gliederung Deutschlands, 6. Lieferung, edited by: Meynen, E., Schmithüsen, J., Gellert, J., Neef, E., MüllerMiny, H., and Schultze, H. J., Selbstverlag der Bundesanstalt für Landeskunde, Remagen, Germany, 722-756, 1959.

BKG (Federal Agency for Cartography and Geodesy): Quasigeoid of the Federal Republic of Germany, The height reference surface of the Working Committee of the Surveying Authorities of the States of the Federal Republic of Germany, GCG2011 (German Combined QuasiGeoid 2011), Federal Agency for Cartography and Geodesy, 7 pp., available at: https://upd.geodatenzentrum. de/docpdf/quasigeoid_eng.pdf (last access: 10 December 2013), 2011.

Blackburn, G. A.: Quantifying Chlorophylls and Caroteniods at Leaf and Canopy Scales: An Evaluation of Some Hyperspectral Approaches, Remote Sens. Environ., 66, 273-285, https://doi.org/10.1016/S0034-4257(98)00059-5, 1998.

Blume, H.-P., Brümmer, G. W., Horn, R., Kandeler, E., KögelKnabner, I., Kretschmar, R., Stahr, K., and Wilke, B.-M.: Scheffer/Schachtschabel, Lehrbuch der Bodenkunde, 16th edn., Springer, Berlin, 569 pp., 2016.

Chernetskiy, M., Gómez-Dans, J., Gobron, N., Morgan, O., Lewis, P., Truckenbrodt, S., and Schmullius, C.: Estimation of FAPAR over Croplands Using MISR Data and the Earth Observation Land Data Assimilation System (EO-LDAS), Remote Sensing, 9, 656, https://doi.org/10.3390/rs9070656, 2017.

Dash, J. and Curran, P. J.: The MERIS terrestrial chlorophyll index, Int. J. Remote Sens., 25, 5403-5413, https://doi.org/10.1080/0143116042000274015, 2004.

Delta-T Devices: ThetaProbe Soil Moisture Sensor Type ML2x, User Manual ML2x-UM1.21, Delta-T Devices Ltd, Burwell, UK, 22 pp., 1999.

de Wit, C. T.: Photosynthesis of leaf canopies, Agricultural Research Reports, 663, Centre for Agricultural Publications and Documentation, Wageningen, The Netherlands, 57 pp., 1965.

Döring, M.: LPG Pflanzenproduktion Andisleben 1:25 000, VEB Geodäsie und Kartographie, Erfurt, Germany, 1988.

DWD (Deutscher Wetterdienst): WebWerdis, Weather Request and Distribution System, available at: https://werdis.dwd.de/, last access: 11 March 2015.

DWD (Deutscher Wetterdienst): Stationslexikon, available at: https://www.dwd.de/DE/leistungen/klimadatendeutschland/ stationsliste.html, last access: 30 August 2016.

Eagelson, P. S.: Ecohydrology, Darwinian Expression of Vegetation Form and Function, Cambridge University Press, Cambridge, UK, 443 pp., 2004. 
ESA (European Space Agency): ESA Earth Observation Campaigns Data, available at: https://earth.esa.int/web/guest/ campaigns, last access: 30 November 2015.

Féret, J.-B., François, C., Asner, G. P., Gitelson, A. A., Martin, R. E., Bidel, L. P. R., Ustin, S. L., le Maire, G., and Jacquemoud, S.: PROSPECT-4 and 5: Advances in the leaf optical properties model separating photosynthetic pigments, Remote Sens. Environ., 112, 3030-3043, https://doi.org/10.1016/j.rse.2008.02.012, 2008.

Gilabert, M.-A. and Meliá, J.: Solar angle and sky light effects on ground reflectance measurements in a citrus canopy, Remote Sens. Environ., 45, 281-293, https://doi.org/10.1016/00344257(93)90111-A, 1993.

Gobron, N.: Leaf Area Index (LAI), in: Terrestrial Essential Climate Variables for Climate Change Assessment, Mitigation and Adaptation, edited by: Sessa, R. and Dolman, H., Food and Agriculture Organization (FAO), Rome, Italy, 32-33, 2008.

Gobron, N., Pinty, B., Verstraete, M. M., and Govaerts, Y.: A semidiscrete model for the scattering of light by vegetation, J. Geophys. Res., 102, 9431-9446, https://doi.org/10.1029/96JD04013, 1997.

Haboudane, D., Miller, J. R., Pattey, E., Zarco-Tejada, P. J., and Strachan, I. B.: Hyperspectral vegetation indices and novel algorithms for predicting green LAI of crop canopies: Modeling and validation in the context of precision agriculture, Remote Sens. Environ., 90, 337-352, https://doi.org/10.1016/j.rse.2003.12.013, 2004.

Haneklaus, S., Brauer, A., Bloem, E. M., and Schnug, E.: Relationship between sulfur deficiency in oilseed rape (Brassica napus L.) and its attractiveness for honeybees, Landbauforsch. Volkenrode, 283, 37-43, 2005.

Hank, T. B., Bach, H., and Mauser, W.: Using a Remote SensingSupported Hydro-Agroecological Model for Field-Scale Simulation of Heterogeneous Crop Growth and Yield: Application for Wheat in Central Europe, Remote Sensing, 7, 3934-3965, https://doi.org/10.3390/rs70403934, 2015.

Hank, T., Locherer, M., Richter, K., and Mauser, W.: Neusling (Landau a.d. Isar) 2012 - a multitemporal and multisensoral agricultural EnMAP Preparatory Flight Campaign, EnMAP Flight Campaigns Technical Report, GFZ Data Services, Potsdam, Germany, 29 pp., https://doi.org/10.2312/enmap.2016.007, 2016.

Harborne, J. B.: Comparative Biochemistry of the Flavonoids, Academic Press, London, UK, 383 pp., 1967.

Hartge, K. H. and Horn, R.: Die physikalische Untersuchung von Böden, Praxis Messmethoden Auswertung, Schweizerbart, Stuttgart, Germany, 178 pp., 2009.

Hiekel, W., Fritzlar, F., Nöllert, A., and Westhus, W.: Die Naturräume Thüringens, Naturschutzreport 21, TLUG (Thüringer Landesanstalt für Umwelt und Geologie), Jena, Germany, 384 pp., 2004.

Hijmans, R. J.: raster: Geographic data analysis and modeling, R package version 2.2-12, available at: https://CRAN.R-project. org/package=raster, last access: 28 February 2014.

Hueni, A. and Bialek, A.: Cause, Effect, and Correction of Field Spectroradiometer Interchannel Radiometric Steps, IEEE J. Sel. Top. Appl., 10, 1542-1551, https://doi.org/10.1109/JSTARS.2016.2625043, 2017.

Ichoku, C., Levy, R., Kaufman, Y. J., Remer, L. A., Li, R.-R., Martins, V. J., Holben, B. N., Abuhassan, N., Slutsker, I., Eck, T. F., and Pietras, C.: Analysis of the performance characteristics of the five-channel Microtops II Sun photometer for measuring aerosol optical thickness and precipitable water vapor, J. Geophys. Res.-Atmos., 107, 4179, https://doi.org/10.1029/2001JD001302, 2002.

INRA EmmaH (French National Institute for Agricultural Research, Mediterranean Environment and Agro-Hydro System Modelisation Laboratory): Welcome to the CAN-EYE web site, available at: https://www6.paca.inra.fr/can-eye, last access: 16 October 2014.

IUSS Working Group WRB: World Reference Base for Soil Resources 2014, update 2015, International soil classification system for naming soils and creating legends for soil maps, FAO (Food and Agriculture Organization of the United Nations), Rome, Italy, World Soil Resources Reports No. 106, 192 pp., 2015.

Jacquemoud, S., Baret, F., and Hanocq, J. F.: Modeling Spectral and Bidirectional Soil Reflectance, Remote Sens. Environ., 41, 123 132, https://doi.org/10.1016/0034-4257(92)90072-R, 1992.

JECAM (Joint Experiment for Crop Assessment and Monitoring): Joint Experiment for Crop Assessment and Monitoring, JECAM Annual Reports, available at: http://www.jecam.org/?/charter/ annual-reports, last access: 3 December 2015.

Jonckheere, I., Nackaerts, K., Muys, B., and Coppin, P.: Assessment of automatic gap fraction estimation of forests from digital hemispherical photography, Agr. Forest Meteorol., 132, 96-114, https://doi.org/10.1016/j.agrformet.2005.06.003, 2005.

Kapnias, D., Milenov, P., and Kay, S.: Guidelines for Best Practice and Quality Checking of Ortho Imagery, Joint Research Centre (JRC), Ispra, Italy, JRC Scientific and Technical Reports EUR 23638 EN-2008, 38 pp., https://doi.org/10.2788/36028, 2008.

Konica Minolta: SPAD 502Plus Chlorophyll Meter, Product Manual, Konica Minolta, Chiyoda, Japan, 23 pp., 2012.

Kort, E.: rtiff: Read and Write TIFF Files, R package version 1.4.4, available at: https://CRAN.R-project.org/package=rtiff, last access: 28 February 2014.

Lewis, P., Gómez-Dans, J., Kaminski, T., Settle, J., Quaife, T., Gobron, N., Styles, J., and Berger, M.: An Earth Observation Land Data Assimilation System (EO-LDAS), Remote Sens. Environ., 120, 219-235, https://doi.org/10.1016/j.rse.2011.12.027, 2012.

Liang, L., Qin, Z., Zhao, S., Di, L., Zhang, C., Deng, M., Lin, H., Zhang, L., Wang, L., and Liu, Z.: Estimating crop chlorophyll content with hyperspectral vegetation indices and the hybrid inversion method, Int. J. Remote Sens., 37, 2923-2949, https://doi.org/10.1080/01431161.2016.1186850, 2016.

Lichtenthaler, H. K. and Buschmann, C.: Chlorophylls and Carotenoids: Measurement and Characterization by UV-VIS Spectroscopy, in: Current Protocols in Food Analytical Chemistry, John Wiley \& Sons, Hoboken, USA, F4.3.1, https://doi.org/10.1002/0471142913.faf0403s01, 2001.

LI-COR: LAI-2200 Plant Canopy Analyzer, Instruction Manual, 4th edn., LI-COR, Lincoln, USA, 204 pp., 2012.

Lilienthal, H. and Schnug, E.: Eignung spektraler Signaturen zur Lokalisierung von Schwefelmangel in Raps mit Hilfe der Fernerkundung, Landbauforsch. Volkenrode, 286, 47-54, 2005.

Lillesand, T. M., Kiefer, R. W., and Chipman, J. W.: Remote Sensing and Image Interpretation, 6th edn., John Wiley \& Sons, Hoboken, USA, 756 pp., 2008. 
Liu, J. G. and Moore, J. M.: Hue image RGB colour composition. A simple technique to suppress shadow and enhance spectral signature, Int. J. Remote Sens., 11, 1521-1530, https://doi.org/10.1080/01431169008955110, 1990.

Markwell, J., Osterman, J. C., and Mitchell, J. L.: Calibration of the Minolta SPAD-502 leaf chlorophyll meter, Photosynth. Res., 46, 467-472, https://doi.org/10.1007/bf00032301, 1995.

Mattia, F., Le Toan, T., Picard, G., Posa, F. I., D'Alessio, A., Notarnicola, C., Gatti, A. M., Rinaldi, M., Satalino, G., and Pasquariello, G.: Multitemporal C-band radar measurements on wheat fields, IEEE T. Geosci. Remote, 41, 1551-1560, https://doi.org/10.1109/TGRS.2003.813531, 2003.

Meier, U. (Ed.): Growth stages of mono- and dicotyledonous plants, BBCH Monograph, 2nd edn., German Federal Biological Research Centre for Agriculture and Forestry, Braunschweig, Germany, 2001.

Milton, E. J., Schaepman, M. E., Anderson, K., Kneubühler, M., and Fox, N.: Progress in field spectroscopy, Remote Sens. Environ., 113, Supplement 1, S92-S109, https://doi.org/10.1016/j.rse.2007.08.001, 2009.

Monteith, J.: Light Interception and Radiative Exchange in Crop Stands, in: Physiological Aspects of Crop Yield, edited by: Eastin, J. D., Haskins, F. A., Sullivan, C. Y., and van Bavel, C. H. M., American Society of Agronomy and Crop Science Society of America, Madison, USA, 89-111, 1969.

Morisette, J. T., Baret, F., Privette, J. L., Myneni, R. B., Nickeson, J. E., Garrigues, S., Shabanov, N. V., Weiss, M., Fernandes, R. A., Leblanc, S. G., Kalacska, M., Sanchez-Azofeifa, G. A., Chubey, M., Rivard, B., Stenberg, P., Rautiainen, M., Voipio, P., Manninen, T., Pilant, A. N., Lewis, T. E., Iiames, J. S., Colombo, R., Meroni, M., Busetto, L., Cohen, W. B., Turner, D. P., Warner, E. D., Petersen, G. W., Seufert, G., and Cook, R.: Validation of global moderate-resolution LAI products: a framework proposed within the CEOS land product validation subgroup, IEEE T. Geosci. Remote, 44, 1804-1817, https://doi.org/10.1109/TGRS.2006.872529, 2006.

Morys, M., Mims, F. M., Hagerup, S., Anderson, S. E., Baker, A., Kia, J., and Walkup, T.: Design, calibration, and performance of MICROTOPS II handheld ozone monitor and Sun photometer, J. Geophys. Res.-Atmos., 106, 14573-14582, https://doi.org/10.1029/2001JD900103, 2001.

Motonaga, Y., Kondou, H., Hashimoto, A., and Kameoka, T.: A method of making digital fruit color charts for cultivation management and quality control, J. Food Agric. Environ, 2, 160-166, 2004.

Mousivand, A., Menenti, M., Gorte, B., and Verhoef, W.: Global sensitivity analysis of the spectral radiance of a soilvegetation system, Remote Sens. Environ., 145, 131-144, https://doi.org/10.1016/j.rse.2014.01.023, 2014.

MPI BGC (Max Planck Institute for Biogeochemistry): Field Experiments and Instrumentation, Gebesee, available at: https://www.bgc-jena.mpg.de/Freiland/index.php/Sites/ GermanyGebesee?userlang=en, last access: 14 December 2015.

NASA (National Aeronautics and Space Administration): MODIS Land Team Validation, available at: https://landval.gsfc.nasa. gov/, last access: 1 July 2016.

Neumann, H. H., Den Hartog, G., and Shaw, R. H.: Leaf area measurements based on hemispheric photographs and leaf-litter collection in a deciduous forest during autumn leaf-fall, Agr. Forest Meteorol., 45, 325-345, https://doi.org/10.1016/01681923(89)90052-X, 1989.

ORNL DAAC (Oak Ridge National Laboratory - Distributed Active Archive Center for Biogeochemical Dynamics): BigFoot Field Data for North American Sites, 1999-2003, available at: http://daac.ornl.gov/BIGFOOT_VAL/guides/BigFoot_Field_ Data.html (last access: 1 July 2016), 2008.

Park, J. K. and Deering, D. W.: Simple radiative transfer model for relationships between canopy biomass and reflectance, Appl. Optics, 21, 303-309, https://doi.org/10.1364/AO.21.000303, 1982.

PCI Geomatics: Geomatica 10, Geomatica OrthoEngine, User Guide, Version 10.3, PCI Geomatics Enterprises, Inc., Ontario, Canada, 210 pp., 2009.

Peddle, D. R., White, H. P., Soffer, R. J., Miller, J. R., and LeDrew, E. F.: Reflectance processing of remote sensing spectroradiometer data, Comput. Geosci, 27, 203-213, https://doi.org/10.1016/S0098-3004(00)00096-0, 2001.

Pfitzner, F., Bollhöfer, A., and Carr, G.: A Standard Design for Collecting Vegetation Reference Spectra: Implementation and Implications for Data Sharing, J. Spat. Sci., 51, 79-92, https://doi.org/10.1080/14498596.2006.9635083, 2006.

Porra, R. J. and Grimme, L. H.: A new procedure for the determination of chlorophylls $\mathrm{a}$ and $\mathrm{b}$ and its application to normal and regreening Chlorella, Anal. Biochem., 57, 255-267, https://doi.org/10.1016/0003-2697(74)90071-2, 1974.

Porter, J. R. and Gawith, M.: Temperatures and the growth and development of wheat: a review, Eur. J. Agron., 10, 23-36, https://doi.org/10.1016/S1161-0301(98)00047-1, 1999.

Purevdorj, T. S., Tateishi, R., Ishiyama, T., and Honda, Y.: Relationships between percent vegetation cover and vegetation indices, Int. J. Remote Sens., 19, 3519-3535, https://doi.org/10.1080/014311698213795, 1998.

Rau, D., Schramm, H., and Wunderlich, J.: Die Leitbodenformen Thüringens, Legendenkartei zu den Bodengeologischen Übersichtskarten Thüringens im Maßstab 1:100000, 2nd edn., in: Geowissenschaftliche Mitteilungen von Thüringen, Beiheft 3, Weimar, Germany, 100 pp., 2000.

R Core Team: R: a language and environment for statistical computing, available at: https://www.R-project.org/, last access: 15 December 2015.

Richter, R. and Schläpfer, D.: Atmospheric/Topographic Correction for Satellite Imagery, ATCOR-2/3 User Guide, Version 9.0.2, 263 pp., available at: www.rese.ch/pdf/atcor3_manual.pdf (last access: 25 October 2017), 2016.

Ridler, T. W. and Calvard, S.: Picture Thresholding Using an Iterative Selection Method, IEEE T. Syst. Man Cyb., 8, 630-632, https://doi.org/10.1109/TSMC.1978.4310039, 1978.

Robinson, D.: A comparison of soil-water distribution under ridge and bed cultivated potatoes, Agr. Water Manage., 42, 189-204, https://doi.org/10.1016/S0378-3774(99)00031-1, 1999.

Robinson, I. and MacArthur, A.: The Field Spectroscopy Facility Post Processing Toolbox User Guide, Post processing spectral data in MATLAB, University of Edinburgh, Edinburgh, UK, 24 pp., 2011.

Ross, J.: The radiation regime and architecture of plant stands, Tasks for Vegetation Science 3, edited by: Lieth, H., Dr. W. Junk Publishers, The Hague, The Netherlands, 420 pp., 1981. 
Ryu, Y., Nilson, T., Kobayashi, H., Sonnentag, O., Law, B. E., and Baldocchi, D. D.: On the correct estimation of effective leaf area index: Does it reveal information on clumping effects?, Agr. Forest Meteorol., 150, 463-472, https://doi.org/10.1016/j.agrformet.2010.01.009, 2010.

Schaepman-Strub, G., Schaepman, M. E., Painter, T. H., Dangel, S., and Martonchik, J. V.: Reflectance quantities in optical remote sensing-definitions and case studies, Remote Sens. Environ., 103, 27-42, https://doi.org/10.1016/j.rse.2006.03.002, 2006.

Solar Light: User's Guide Microtops II Sunphotometer, Version 5.6, Solar Light Company, Inc., Glenside, USA, 53 pp., 2007.

Stevens, A. and Ramirez-Lopez, L.: prospectr: Miscellaneous functions for processing and sample selection of vis-NIR diffuse reflectance data, $\mathrm{R}$ package version 0.1 .3 , available at: https: //cran.r-project.org/web/packages/prospectr/index.html, last access: 17 December 2013.

TLL (Thüringer Landesanstalt für Landwirtschaft): Anpassung der Thüringer Landwirtschaft an den Klimawandel, Thüringer Ministerium für Landwirtschaft, Naturschutz und Umwelt, Jena, Germany, 12 pp., 2009.

TLUG (Thüringer Landesamt für Umwelt und Geologie): Digitale Bodengeologische Konzeptkarte 1:50 000, TLUG, Weimar, Germany, 2000.

TLUG (Thüringer Landesamt für Umwelt und Geologie): Bodenkarte von Thüringen 1:50000, Blatt L 4930, Erfurt NW, TLUG, Jena, Germany, 2002.

TLVA (Thüringer Landesvermessungsamt): Topographische Karte $1: 10000$, Blatt 4831-SW, Herbsleben, TLVA, Erfurt, Germany, 2003.

TLVermGeo (Thüringer Landesamt für Vermessung und Geoinformation): Topographische Karte 1:10000, Blatt 4931-NO, Walschleben, TLVermGeo, Erfurt, Germany, 2006.

TLVermGeo (Thüringer Landesamt für Vermessung und Geoinformation): Digitales Geländemodell 5 (DGM 5), TLVermGeo, Erfurt, Germany, 2008.

TLVermGeo (Thüringer Landesamt für Vermessung und Geoinformation): Topographische Karte 1:10 000, Blatt 4831-SO, Gebesee, 2nd edn., TLVermGeo, Erfurt, Germany, 2010.
TLVermGeo (Thüringer Landesamt für Vermessung und Geoinformation): Topographische Karte 1:10000, Blatt 4931-NW, Dachwig, 2nd edn., TLVermGeo, Erfurt, Germany, 2012.

TLVermGeo (Thüringer Landesamt für Vermessung und Geoinformation): SAPOS, Koordinaten der Referenzstationen (ETRS89 und PD83), available at: https://sapos.thueringen.de/download.php, last access: 26 July 2016.

Truckenbrodt, S. C. and Baade, J.: Gebesee Database for the enhancement of crop monitoring applications: evolution of plant physiology, soil moisture, surface reflectance and atmospheric conditions on the agricultural Gebesee test site (central Germany) in 2013 and 2014, PANGAEA, https://doi.org/10.1594/PANGAEA.874251, 2017.

USDA (United States Department of Agriculture): Foreign Agricultural Service, World Agricultural Production (April 2015), USDA, Washington, 7 pp., available at: http://usda.mannlib.cornell.edu/MannUsda/viewDocumentInfo. do?documentID=1860 (last access: 5 October 2016), 2015.

Weiss, M. and Baret, F.: CAN-EYE V6.313 User Manual, EmmaH and INRA Science \& Impact, 44 pp., available at: https://www6.paca.inra.fr/can-eye/Documentation-Publications/ Documentation, last access: 16 October 2014.

Weiss, M., Baret, F., Smith, G. J., Jonckheere, I., and Coppin, P.: Review of methods for in situ leaf area index (LAI) determination: Part II. Estimation of LAI, errors and sampling, Agr. Forest Meteorol., 121, 37-53, https://doi.org/10.1016/j.agrformet.2003.08.001, 2004.

$\mathrm{Xu}, \mathrm{X}$., Han, G., and Min, H.: A novel algorithm for associative classification of image blocks, in: Proceedings of the Fourth International Conference on Computer and Information Technology (CIT '04), Wuhan, China, 14-16 September 2004, 46-51, https://doi.org/10.1109/CIT.2004.1357173, 2004.

Zech, W., Schad, P., and Hintermaier-Erhard, G.: Böden der Welt, Ein Bildatlas, 2nd edn., Springer, Berlin, Germany, 164 pp., 2014.

Zou, X. and Mõttus, M.: Retrieving crop leaf tilt angle from imaging spectroscopy data, Agr. Forest Meteorol., 205, 73-82, https://doi.org/10.1016/j.agrformet.2015.02.016, 2015. 